\title{
Metallic nanoparticles for electrocatalytic reduction of halogenated organic compounds: a review
}

\author{
Yao-Yin Lou ${ }^{\mathrm{a}, \mathrm{b}}$, Jean-Marie Fontmorin ${ }^{\mathrm{a}}$, A. Amrane ${ }^{\mathrm{b}}$, F. Fourcade ${ }^{\mathrm{b}}$, F. Geneste *a $^{\mathrm{a}}$ \\ ${ }^{a}$ Univ Rennes, CNRS, ISCR [(Institut des Sciences Chimiques de Rennes)] - UMR 6226, \\ F-35000 Rennes, France \\ ${ }^{\mathrm{b}}$ Univ Rennes, Ecole Nationale Supérieure de Chimie de Rennes, CNRS, ISCR [(Institut \\ des Sciences Chimiques de Rennes)] - UMR 6226, F-35000 Rennes, France \\ Highlights \\ - A review on nanoparticles-modified electrodes for reductive dehalogenation. \\ - The 3D supports for nanoparticles are compared. \\ - Methods to prepare and characterize nanoparticles on porous electrode support. \\ - The influence of the electrode material on electro-dehalogenation process is \\ discussed. \\ - Recent applications of nanoparticles-modified electrodes to treat halogenated \\ compounds.
}

\begin{abstract}
Increasing attention is paid to the degradation of refractory halogenated organic compounds in wastewaters. For this purpose, electrocatalytic reduction process constitutes a promising technology due to its high selectivity. Owing to their wellcontrolled structure and high specific surface area, nanoparticles have been the subject of many investigations in electrocatalysis. This study presents a general review on nanoparticles-modified electrodes to achieve reductive dehalogenation. The role of the electrode support, especially 3-D Carbon and metallic porous electrodes are first discussed. Then, the methods to prepare metallic nanoparticles on the electrode supports included spontaneous deposition and/or electrodeposition are summarized and the commonly used characterization methods of nanoparticles modified electrodes are also presented. The influence of the electrode material, $\mathrm{Ag}, \mathrm{Pd}$, and $\mathrm{Cu}$, as representatives, on electro-dehalogenation process is discussed and compared. Finally, this review also highlights the recent applications of these nanoparticles-modified electrodes for the treatment of halogenated organic compounds in aqueous solutions.
\end{abstract}




\section{Keywords}

Electroreduction; nanoparticles; halogenated organics; deposition; pollutants

\section{Introduction}

The accumulation of persistent organic pollutants (POPs) in the environment has disastrous ecological impacts. POPs, and particularly chlorinated organic compounds such as polychlorinated biphenyls (PCBs), polychlorinated dibenzo-p-dioxins and other organochlorine pesticides can be stored in fatty tissues of wild species leading to a wide range of effects, for example, neurotoxicity, behavioral changes, hormonal disruption, and reproductive problems [1]. The contamination of water, air, food and consumer products such as textiles and packaging by POPs may also have severe impacts on human health as there are potential links between POPs exposure and diseases including hormone-dependent cancers, reproductive health issues and metabolic disorders [1]. Organohalogenated compounds are recalcitrant to degradation, hence inevitably leading to their accumulation in different environmental compartments and increasing the risks of animal and human exposure. For example, a survey on POPs in samples from woodland and grassland surface soil collected along an existing latitudinal UK-Norway transect showed the occurrence of short-chain chlorinated paraffin as the main pollutant $(35 \pm 100$ $\mathrm{ng} / \mathrm{g}$ soil organic matter (SOM)), followed by endosulfans $\left(3 \pm 3 \mathrm{ng} \mathrm{g}^{-1} \mathrm{SOM}\right)$ and pentachlorobenzene $\left(1 \pm 1 \mathrm{ng} \mathrm{g}^{-1} \mathrm{SOM}\right)$ [2].

Conventional physical and biological treatments cannot totally degrade recalcitrant organohalogenated compounds thus leading to partially dehalogenated and still toxic substances being discharged in surface waters. Alternatives have been developed to tackle this issue, especially advanced oxidation processes (AOPs), which are based on the generation of highly reactive and unselective radicals, typically hydroxyl radicals $(\cdot \mathrm{OH})$. Among them, photocatalytic oxidation [3], Fenton oxidation [4], sonoelectrochemical treatments [5] and electrooxidation [6, 7] have been throughly studied in the past, showing promising results for the degradation of POPs in both synthetic and real effluents. Despite the very strong oxidative power of hydroxyl radicals $\left(\mathrm{E}^{0}\left(\cdot \mathrm{OH} / \mathrm{H}_{2} \mathrm{O}\right)=\right.$ $2.80 \mathrm{~V}$ vs SHE [8]), the complete mineralization of the effluent can be challenging to achieve due to the formation of more resistant by-products, therefore significantly increasing the time and cost of treatment [9]. In order to limit the cost of these technologies and make them more energy-efficient, AOPs and more generally physicochemical processes can be coupled with more classical biological processes [9, 10]. Depending on the nature of the effluent (load in chemical oxygen demand, toxicity, etc.), physico-chemical technologies can either be used as pre- or post-treatment. In presence of toxic substances, the aim of the pre-treatment is to increase the biodegradability of the 
effluent (or reduce its toxicity) prior to the biological treatment. The relevance of coupling AOPs such as photocatalysis or electro-Fenton with a biological process for the degradation of effluents contaminated with recalcitrant organic compounds has been demonstrated in the past [10-15]. Electrochemical processes can also be used as pre- or post-treatment to directly oxidize or reduce organic compounds by tuning the potential or the current applied according to the target compound, hence making them more selective than AOPs. For example, processes based on electrochemical oxidation or reduction coupled with activated sludge treatment were reported for the removal of antibiotics and pesticides [16-22].

It is well-known that the presence of chlorine atoms in organic compounds is related to their toxicity [23]. Therefore, the removal of chlorine atoms from organohalogenated compounds is expected to decrease their toxicity and improve their biodegradability [24]. By selectively targeting carbon-chlorine bonds, reductive dechlorination is thus a promising approach to reduce the toxicity of chlorinated organic compounds prior to a biological treatment. Among these reductive dechlorination techniques, electroreduction has been particularly investigated because the whole process can be performed in mild conditions [25]. However, direct reductive dechlorination is challenging to achieve in aqueous media due to the competition with the hydrogen evolution reaction (HER). Therefore, in order to decrease the overpotentials needed to drive the dechlorination reaction and to reduce the energy consumption, catalysts are required. Metal catalysts such as $\mathrm{Ag}$ [26, 27], Pd [28], $\mathrm{Cu}$ [29, 30], $\mathrm{Ni}$ [31, 32], Au [33], and Pt [34] have shown a good electrocatalytic ability to cleave $\mathrm{C}-\mathrm{X}$ bonds (where $\mathrm{X}=\mathrm{Cl}, \mathrm{Br}$, or I), allowing their reduction at less negative potentials than on carbon electrodes. However, from an economic point of view, using high surface of noble metallic catalyst is not realistic. An interesting alternative is the utilization of nanoparticles (NPs) on carbon material supports. NPs have a hierarchical structure with high specific surface area and abundant active sites, making them particularly interesting for catalysis [35-41]. Furthermore, because of their high surface-to-volume ratio, it is possible to obtain high current densities with a low loading of NPs, thus enhancing the efficiency of the reaction, while decreasing the reaction time. Moreover, the electrocatalytic activity of metallic NPs is often similar or even higher than bulk metal. For example, Ag nanoclusters supported on glassy carbon and bulk Ag have shown comparable electrocatalytic activities, anticipating a positive shift of the reduction potential of $\mathrm{PhCH}_{2} \mathrm{Cl}$ by ca. $0.5 \mathrm{~V} / \mathrm{SCE}$ compared with bare glassy carbon [42]. It has also been reported that $\mathrm{Cu}$ nanostructured electrodes tend to be more efficient than bulk $\mathrm{Cu}$ towards the reduction of organic chlorides [43].

However, NPs are a potential threat to aqueous organisms and human health [44, 45]. For example, Yue et al. [46] reported that Ag NPs can be taken up by fish cells via endocytic 
pathways, bind to both extracellular and intracellular proteins and inhibit enzyme activity. For a more sustainable process, NPs should therefore be strongly immobilized on the electrode surface to prevent them from being released into the effluent during the dechlorination reaction. The NPs immobilized on electrode support are usually stable even after several electrolyses $[47,48]$.

The role of electrocatalysis in the remediation of water pollutants has been recently reviewed, underlining its interest for decentralized water treatment [49]. This review paper aims to give a critical overview on the development of electrodes modified by nanoparticles for the reductive dechlorination of POPs. In a first part, the methods used for the preparation and characterization of NPs will be discussed. The second part will focus on the effect of nanoparticles composition and structure on the electroreduction efficiency. Finally, the main results on the electrocatalytic reduction of biorecalcitrant compounds with nanoparticles modified electrodes will be summarized.

\section{Preparation of electrode materials with nanoparticles}

The role of the electrode material for electrocatalysis is essential. A high specific surface area, a good electrical conductivity and a high catalytic activity are required. To achieve this goal, the electrode material needs to be an appropriate support with a fine dispersion of the metallic NPs on its surface. Moreover, it has been reported that the modulation of NPs electronic properties by interaction with the chemical or morphological defects of the support can increase the catalytic activity and selectivity of the electrode material [47].

\subsection{Supports used for NPs deposition}

There is a large choice of $3 \mathrm{D}$ electrodes that are often preferred for electrocatalytic applications owing to their high specific surface area and to the possibility to use them in flow systems.

\subsubsection{Carbon support}

Carbon supports, including glassy carbon felt, graphene foam, and graphite felt (Fig. 1), are considered as good candidates since they offer high specific surface area and chemical inertness. It has also been reported that carbon supports are able to adsorb organic halide compounds, leading to the enhancement of the catalytic efficiency of the electrode material [50]. Kopinke et al. [50] exhibited a beneficial interplay between the adsorptive properties of activated carbon and the reductive dechlorination by Fe NPs immobilized on it. Interestingly, the activated carbon served as a redox mediator between the Fe NPs and the adsorbed species. The enhancement of the electroreduction process by adsorption of organic halides on activated carbon is particularly interesting for wastewater treatment for which the target components are often in low concentration 
(usually $\leq 100 \mathrm{mg} \mathrm{L}^{-1}$ ). Another attractive property of carbon substrates is the presence of oxygen and nitrogen functional groups, including carboxyl, phenol, hydroxyl, epoxy, amino groups and lactones on their surface. These functional groups are formed by the oxidation of the edge-plane sites and defects on the surface of carbon [51, 52]. The amount and the nature of surface oxides are influenced by the method used to modify, to clean and to activate the substrate [53]. These functional groups play an essential role in the electrocatalytic process. For example, it has been shown that oxygen groups can enhance the catalytic activity of Ag NPs for dechlorination of halogenated organic compounds, imparting hydrophilicity to the carbon surface [54]. Carbon materials, however, are known for their limited electrical conductivity that can be nevertheless improved with graphene material, and for their low catalytic activity compared with metals. For these reasons, metallic supports have also been widely investigated.

\subsubsection{Metallic support}

Three-dimensional metal electrodes such as $\mathrm{Cu}$ foam [55], Fe mesh [56], $\mathrm{Ti} / \mathrm{TiO}_{2}$ nanotubes [57] Ti mesh [58] and $\mathrm{Ni}$ foam [32] (Fig. 1) are good alternatives to carbon materials, since they have low electrical resistance and sufficient reactive sites due to their appreciable surface area. Metal foams with various void volume fractions have a high surface area (typically between $200-400 \mathrm{~cm}^{2} \mathrm{~cm}^{-3}$ ) as well as good porosity and penetrability that favor reactant mass transfer (the pore diameters are typically in the range of $0.2-0.5 \mathrm{~mm}$ ) [55, 59]. Moreover, they also present high electrical and thermal conductivity, good mechanical strength and corrosion resistance, which make them excellent candidates as electrode supports for electrocatalysis [59-61]. Compared with Pd-loaded activated carbon materials, palladized $\mathrm{Ni}$ foam has shown a better catalytic activity toward the hydrodechlorination of 4-chlorobiphenyl with high chloride removal performance and good electrode stability [56]. This result has been attributed by the authors to the much more open area of $\mathrm{Ni}$ foam than activated carbon matrix, for which severe mass-transport limitation could occur, when a significant amount of $\mathrm{H}_{2}$ is generated. Cheng et al. [62] also obtained 20\% higher current efficiency and saved 50\% energy consumption by using Ti mesh instead of activated carbon cloth as a cathode substrate for the electrochemical hydrodehalogenation of 2,4-dichlorophenol (DCP). This is a consequence of the higher current efficiencies and also of the lower resistance of the Ti mesh, compared with the carbon cloth. Better mass transport of DCP at the Ti mesh can be expected because of its very open structure, leading to better hydrodehalogenation performances, compared with carbon cloth. 


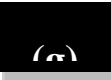



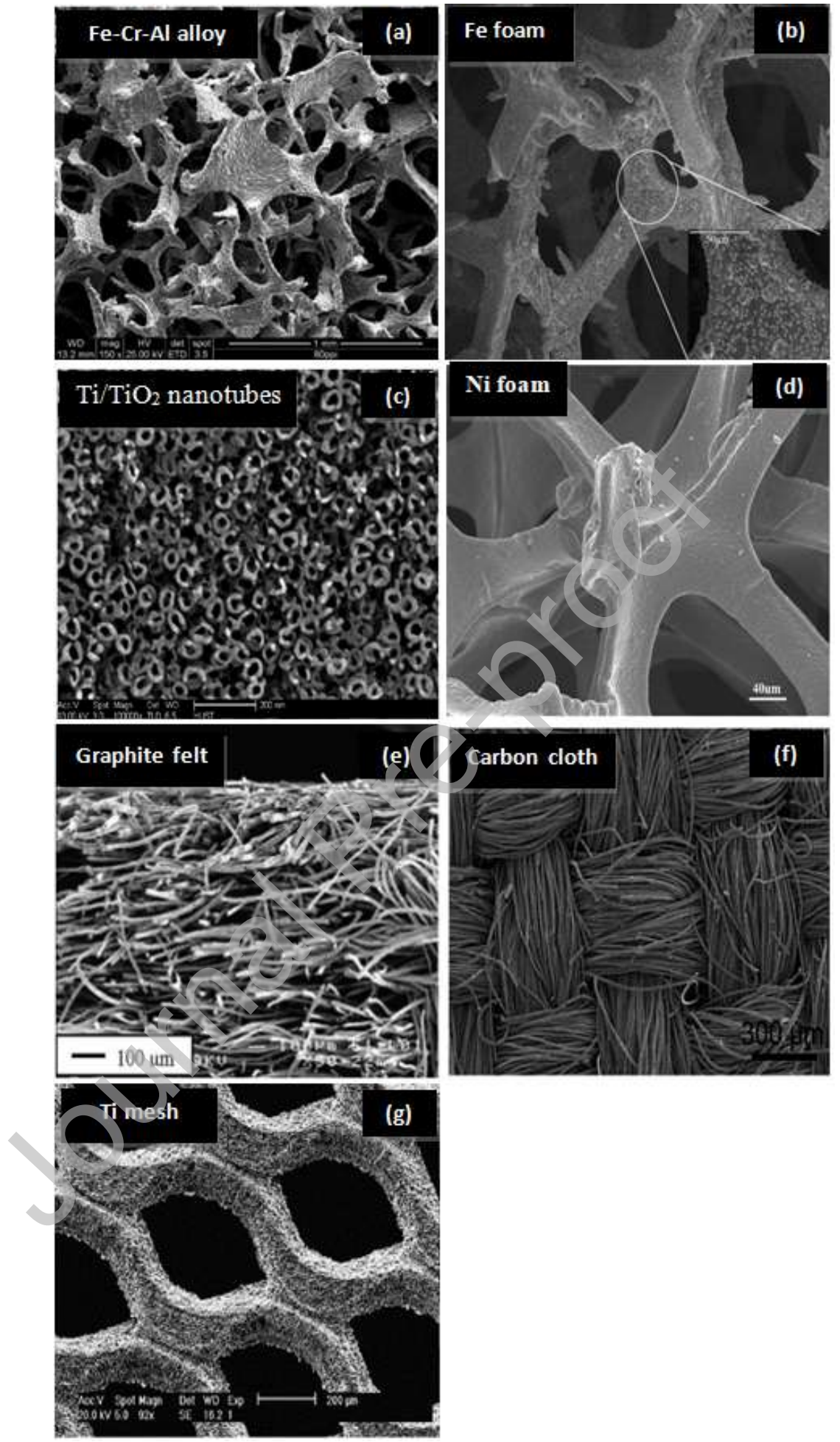

Fig. 1. Scanning Electron Microscope (SEM) images of some porous, 3-D electrodes supports. (a) $\mathrm{Fe}-\mathrm{Cr}-\mathrm{Al}$ alloys [63]; (b) $\mathrm{Fe}$ foam [56]; (c) $\mathrm{Ti}^{-} \mathrm{TiO}_{2}$ nanotubes [57]; (d) $\mathrm{Ni}$ foam [32]; (e) Graphite felt [64]; (f) Carbon cloth [65]; (g) Ti mesh [58]. 
Some electrocatalytic metals, such as $\mathrm{Ag}, \mathrm{Pd}, \mathrm{Cu}$, and $\mathrm{Au}$, do not usually have high surface areas, resulting in insufficient active sites for target compounds. However, it can be interesting to use them as support for nanoparticles when for example a synergistic effect can be expected between them and the deposited metallic nanoparticles. Thus rough surface treatments based on the oxidation-reduction cycle (ORC) process have been developed to enhance their specific surface area and roughness, leading to more exposed active sites [26]. The ORC process consists for example in the oxidation and then the reduction of polished $\mathrm{Ag}$ for several minutes in alkaline or neutral aqueous solutions containing $\mathrm{KCl}$ or $\mathrm{K}_{2} \mathrm{SO}_{4}$. This treatment leads to a porous film with many columnar and extruded NPs on its surface, as shown in Fig. 2. The specific surface area of the roughened Ag support is nearly 300 times higher than that of untreated Ag. As a result, cyclic voltammetry analysis shows that the reduction peak of a polyhalogenated phenol increased nearly nine-fold after ORC treatment of the Ag electrode. Furthermore, the potential peak shifts to positive values with the roughened electrode. Thus, the ORC process significantly improves the surface characteristics and enhances the catalytic activity of the electrode. As an example to show the efficiency of the ORC process, a Pdmodified Ag electrode with a surface-roughened treatment can remove 2,4Dichlorophenoxyacetic acid with a $27 \%$ higher conversion within two hours than untreated Pd-Ag electrode with an optimal current efficiency of 30\% [66].
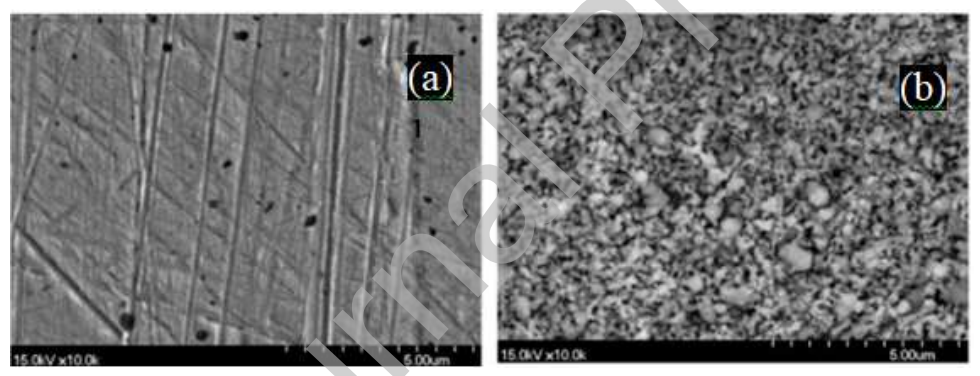

Fig. 2. SEM images: (a) Ag (pristine) electrode, (b) Ag (roughened) electrode [66].

\subsubsection{Doping methods}

To obtain better electrocatalytic ability of cathodes, it is possible to dope the support with heteroatoms. It has been widely used to improve the conductivity of carbon substrates. For carbon, the most used heteroatom dopants include nitrogen, boron, and phosphorus [67-69]. The role of doping agents can be classified as follows [47, 67, 70, 71]:

\section{(1) enhancement of internal electrical properties of carbon materials;}

M. Terrones et al. [69] found that N-doped carbon nanotubes had much better electrical conductivity than pure carbon nanotubes. The improvement of the electrical conductivity can provoke the increase of the current efficiency and the decrease of the electroreduction time. Both electron and hole doping result in a change in the graphene lattice [72]. 


\section{(2) increase of surface oxide functional groups of carbon;}

Doping techniques can enrich the surface oxide functional groups, including stable semiquinone and carbonyl groups, unstable carboxyl, acid anhydride and lactone groups [67]. These oxide species could promote metal nanoparticles deposition as well as enhance the stability of NPs on the support surface $[54,68]$.

Carbon support can be treated with concentrated $\mathrm{HNO}_{3}$ at about $120{ }^{\circ} \mathrm{C}$ to enrich its surface in oxygen (mainly carboxylic groups), leading to the increase of its hydrophilicity. Thus, oxo-groups on carbon surface allows for the possibility to reach the real metallic catalysts loading on carbon matrix, by effectively clamping the electrocatalytic nanoparticles during the preparation of nanoparticles modified carbon support. The hydrophilicity of the carbon surface favors its interaction with organic molecules in the presence of water, making the bond cleavage and electron transfer process faster [54]. For example, Durkić et al. [73] prepared glassy carbon by the carbonization of a commercial resol type of phenol-formaldehyde resin mixed with phosphorus pentoxide and boric acid before polymerization. They found that boron and phosphorus were incorporated substitutionally into the carbon lattice, leading to the increase of the number of surface oxygen groups and to the improvement of the stability of surface oxygen species on the doped glassy carbon. Perić-Grujić et al. [67] spontaneously deposited Ag and Pd on the above modified glassy carbon. They reported that the highest amount of $\mathrm{Ag}$ and Pd deposits were obtained at the electrode surface that contained the highest quantity of surface oxide complexes. It has been concluded that carboxyl groups are involved in the deposition process.

\section{(3) increase of the chemical and structure defects of carbon.}

The doping techniques can also increase the chemical and structure defects, resulting in an increased number of edges and providing the initial nucleation centers to form NPs [74]. Perini at al. [47] have found that morphological defects can act as trapping sites to anchor the catalyst NPs. The authors synthesized a modified nitrogen-glassy carbon support by $\mathrm{N}_{2}^{+}$and $\mathrm{N}^{+}$ions implantation into glassy carbon. It was reported that the $\mathrm{Pd}$ NPs on the nitrogen-doped glassy carbon support were about 50\% smaller with increased distribution and improved activity toward the $\mathrm{C}-\mathrm{Cl}$ bond cleavage (peak potential positively shifted in cyclic voltammetry) in comparison with Pd NPs on pristine glassy carbon [47].

As pristine metallic electrodes are already very conductive by nature, there are not a lot of examples of doping metal electrodes. However, it is for example interesting to underline the physicochemical features of nanosized titanium nitride [75]. Nanosized 
titanium nitride has a good chemical stability, a low electrical resistivity and an attractive catalytic ability. It has been shown that a better catalytic activity toward the reductive dechlorination of 2,4-dichlorophenoxyacetic acid can be observed with $\mathrm{Pd} / \mathrm{Ni}$ foam electrodes doped with nanosized titanium nitride, compared to a non-modified $\mathrm{Pd} / \mathrm{Ni}$ foam electrode. The good electrical conductivity of nanosized titanium nitride accelerates the electron transfer inside the Pd layer, enhancing the cathode current compared with undoped electrode materials. Moreover, the nanosized titanium nitride doping effect induces more polarized portion for hydrogen evolution reaction, increasing the number of active hydrogen atoms $[\mathrm{H}]$ chemisorbed on $\mathrm{Pd}$ available for the dechlorination process.

\subsubsection{Novel supports}

3-dimensional supports, which possess high specific surface areas can also be covered by a conductive layer to support NPs. Thus, the moderate conductivity of carbon felt can be improved by covering the surface of its fibers by a metallic layer. It has been performed with Ni-coated graphite felt by Floner and Geneste [64], who developed a new 3dimensional electrode material by electrodeposition of a Ni layer onto a graphite felt. The Ni-coated graphite felt shown in Fig. 3 combined the high specific surface area of the graphite felt with the good conductivity of $\mathrm{Ni}$. The specific surface area of the $\mathrm{Ni}$-coated graphite felt was estimated by Brunauer, Emmett and Teller (BET) to $1 \mathrm{~m}^{2} \mathrm{~g}^{-1}$, which is higher than the surface area of the traditional Ni foams $\left(10^{-3}\right.$ to $\left.2 \times 10^{-2} \mathrm{~m}^{2} \mathrm{~g}^{-1}\right)$. In addition, the electrical conductivity of the Ni-coated graphite felt is enhanced because of the lower electrical resistivity of $\mathrm{Ni}(69.9 \mathrm{n} \Omega \cdot \mathrm{m})$ than that of graphite (2500 to 5000 $\mathrm{n} \Omega \cdot \mathrm{m}$ ) [76]. $\mathrm{Cu}$ - and Bi-coated carbon felts have also been reported [77-79]. Cu-coated graphite felts possess high electrical and thermal conductivities, and their wear-resistant properties (with fiber content above $10 \mathrm{vol} \%$ ) are superior to those of wear-resistant $\mathrm{Cu}$ alloys.

Nanoporous Ag foam onto a glassy carbon electrode (GCE) has also been reported [80]. To do so, a solution containing $0.01 \mathrm{M}$ of $\mathrm{AgBF}_{4}$ and $2 \mathrm{M}$ of $\mathrm{HBF}_{4}$ was prepared and a high current density of $3 \mathrm{~A} \mathrm{~cm}^{-2}$ was applied to a $2 \mathrm{~cm}^{2} \mathrm{GCE}$ for $60 \mathrm{~s}$. A foam-like structure was obtained with $40 \mathrm{~nm}$ Ag crystals assembled in irregular ca. 70-300 nm thick filaments. It would constitute an interesting support for NPs deposition owing to its good reductive dehalogenation properties. 

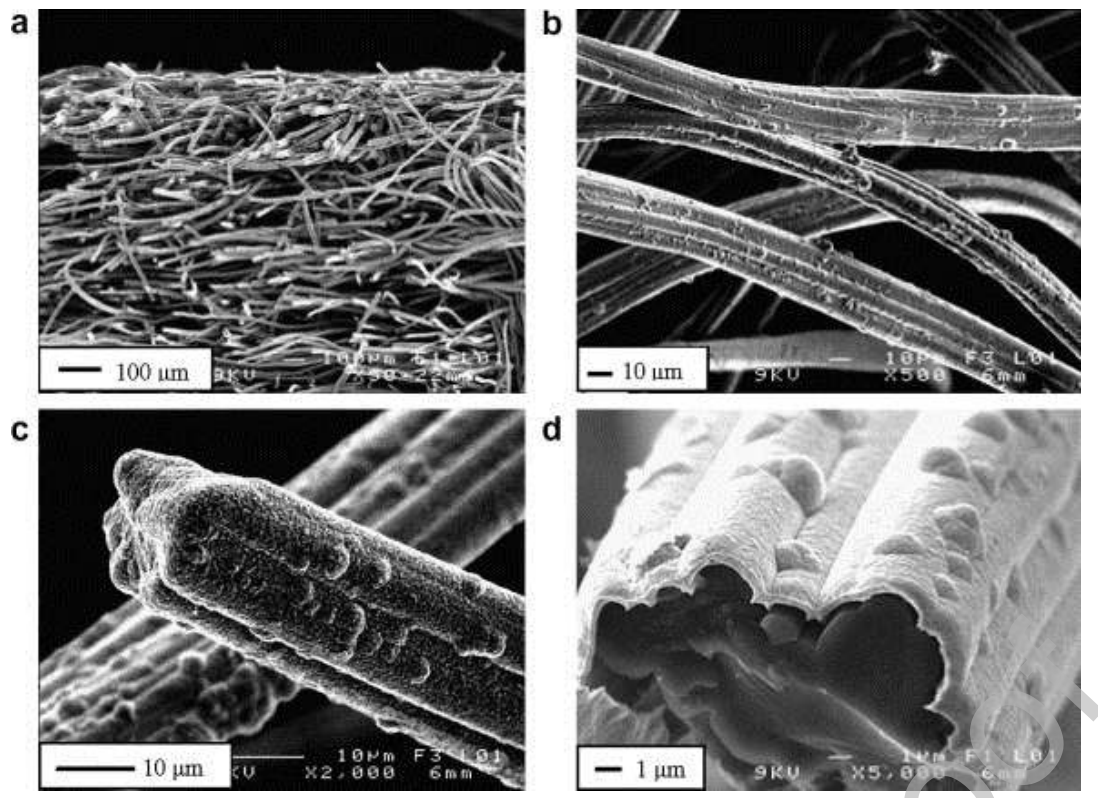

Fig. 3. SEM images of a Ni-coated graphite felt [64]

Nano-porous silicon flour has also been reported as NPs electrode support [81]. It was prepared by first etching polycrystalline $\mathrm{Si}$-flour in aqueous solutions containing $\mathrm{HF}$ and $\mathrm{HNO}_{3}$. Then Ag NPs were formed by electroless deposition and removed by soaking in $\mathrm{HNO}_{3}$ solution. The removal of Ag NPs created nanostructure of silicon flour. This material was then modified with $\mathrm{Pt}, \mathrm{Pt}-\mathrm{Pd}, \mathrm{Pt}-\mathrm{Rh}$ and $\mathrm{Pt}-\mathrm{Ru}$ NPs and deposited on a graphene electrode. Such electrodes are good potential candidates for hydrodehalogenation of organic halides.

\subsection{Preparation of electrodes modified with NPs}

Numerous methods have been exploited for the deposition of NPs on electrode supports for electrochemical dehalogenation, which can be classified as follows: chemical reduction, galvanic displacement deposition, and electrodeposition.

\subsubsection{Chemical reduction}

Chemical reduction is a common method to form NPs onto a 3D support. For example, Feng et al. [82] produced in situ bimetallic $\mathrm{Co}_{\mathrm{x}} \mathrm{Ni}_{1-\mathrm{x}}$ (with $\mathrm{x}=0,0.1,0.3,0.5,0.7,0.9,1$ ) NPs (mean particle size $6.5 \mathrm{~nm}$ ) adhered on graphene, using a one-step procedure. The bimetallic NPs were formed using a $\mathrm{Co}^{2+}$ and $\mathrm{Ni}^{2+}$ solution in the presence of sodium borohydride and methylamine borane used as reducing agents. A common reducing agent is $\mathrm{N}_{2} \mathrm{H}_{4}$ [83], but other alternative synthetic methods are also proposed. Thus, Wang and Wang [84] have developed new methods using hot hydrogen or formaldehyde as reducing agents to synthesize Pd NPs on activated carbon surface. The Pd NPs had a 
narrow distribution with a mean particle diameter of about $4.1 \mathrm{~nm}$ using hot hydrogen and $5.2 \mathrm{~nm}$ using formaldehyde.

\subsubsection{Spontaneous deposition}

Spontaneous deposition of NPs onto the electrode support, also known as galvanic replacement or transmetallation, is an electroless method occurring at open circuit potential. It "spontaneously" produces ad-layers of most metals, which strongly interact with the substrate and produce a bi-metallic electrode, as described in the equation (1).

$M_{\text {nano }}^{n+}+\frac{n}{m} M_{\text {substrate }} \rightarrow M_{\text {nano }}+\frac{n}{m} M_{\text {substrate }}^{m+}$

Where $\mathbf{M}_{\text {substrate }}$ is the metal substrate or the substrate covered by a layer of metal; and $\mathrm{M}_{\text {nano }}$ is the metallic nanoparticle.

This reaction is a thermodynamically favored process if the standard potential of the metal substrate $\left(\mathrm{E}^{0}{ }_{\mathrm{M} \text {-substrate }}\right)$ is lower than the standard potential of the NPs $\left(\mathrm{E}^{0}{ }_{\mathrm{M} \text {-nano }}\right)$, $E_{M-\text { substrate }}^{0}<E_{M-\text { nano. }}^{0}$.

Spontaneous deposition methods can be performed with metallic supports, such as $\mathrm{Ni}, \mathrm{Ag}$ and $\mathrm{Cu}$ electrodes $[70,85,86]$ or with inert electrodes covered by a metallic layer.

It is worth noting that the passivation of the metallic support can prevent the galvanic displacement reaction, even if the deposition is thermodynamically favorable $\left(\mathrm{E}_{\mathrm{M} \text {-substrate }}^{0}<\mathrm{E}_{\mathrm{M} \text {-nano }}^{0}\right)$. Thus, E. Verlato et al. [87] found that $\mathrm{Ag}$ deposition and $\mathrm{Ni}$ dissolution could not occur simultaneously in nitrate solution. However, favorable conditions for $\mathrm{Ni}-\mathrm{Ag}$ galvanic exchange were obtained with sodium thiosulfate, as shown in Fig. 4. It appeared that no passivation phenomenon occurred on $\mathrm{Ni}$ in this medium, and a negative shift of its oxidation potential was observed. This shift was enough to allow the galvanic displacement reaction to occur even if the reduction potential of $\mathrm{Ag}$ complexed by thiosulfate was also more negative.

Pd NPs have also been synthesized on Ni foam by galvanic displacement reaction [75]. During $\mathrm{Pd}$ deposition, the excess of $\mathrm{Cl}^{-}$ions is added to form a $\left[\mathrm{PdCl}_{4}\right]^{2-}$ complex in order to increase the solubility. 

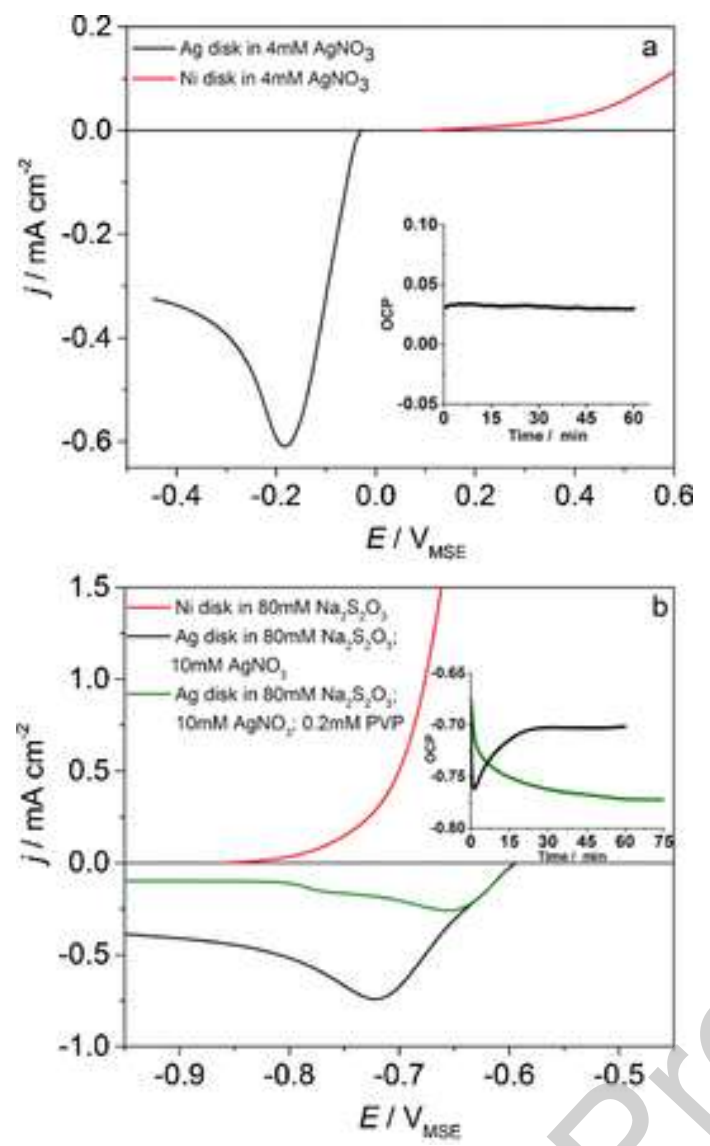

Fig. 4. Voltammetric curves relevant to $\mathrm{Ni}$ electrodissolution and $\mathrm{Ag}$ deposition in solutions of nitrate (a) and thiosulfate (b). Anodic and cathodic curves were recorded with $\mathrm{Ni}$ and $\mathrm{Ag}$ disc electrodes, respectively. The insets show the dependence of the open-circuit potential (OCP) of a $\mathrm{Ni}$ disc electrode dipped in the solutions used for galvanic displacement [87].

\subsubsection{Electrodeposition}

In recent decades, the electrochemical process to obtain NPs on support surface has attracted a lot of attention. In this case, the metal catalyst is deposited by electrochemical reduction of metal ions, according to equation (2):

$M_{\text {nano }}^{n+}+n e^{-} \rightarrow M_{\text {nano }}$

Electrodeposition can lead to heterogeneous deposits, due to uneven current distribution on the different surface areas of 3D electrodes [59]. As an example, during electrodeposition of $\mathrm{Ni}$ onto graphite felt [64], the surface of the felt facing the counter electrode is at a higher potential than the fibers inside the felt. The potential of the fibers decreases as the distance between the fibers and the surface of the felt increases. As a 
result, the Ni loading on the external faces is higher than inside the material. However, electrodeposition has some advantages summarized as follows [88]:

(1) the size and density of NPs can be controlled by the applied current or potential value;

(2) the time required for the formation of stable NPs is short;

(3) the loading of metal onto the support can be monitored through the electrolysis charge.

There are several methods used to perform electrodeposition: using a constant current $[29,89]$ or a constant potential $[47,90]$, or by pulsed techniques $[43,91]$.

\section{Constant current intensity or constant potential electrodeposition}

Galvanostatic and potentiostatic techniques consist in applying a constant current intensity [92] or potential [93], respectively, until the end of the deposition. These methods are easy and straightforward to operate [59]. Zhao et al. [48] and Li et al. [94] compared the $\mathrm{Pd} / \mathrm{Fe}$ NPs modified carbon paper synthesized by chemical reduction on the one hand and by galvanostatic electrodeposition process on the other hand. After impregnation followed by calcination of the carbon paper with $\mathrm{Pd}^{2+}$ ions and then $\mathrm{Fe}^{2+}$ ions, the chemical reduction was carried out with hydrogen as the reducing agent at $200^{\circ} \mathrm{C}$ for $120 \mathrm{~min}$. Regarding the electrodeposition process, it was performed at $1 \mathrm{~mA}$ $\mathrm{cm}^{-2}$ for $30 \mathrm{~min}$. Homogeneous distribution and finer particle size of Pd NPs were obtained with the electrodeposition process (about $20 \mathrm{~nm}$ in diameter), while Pd NPs obtained in the case of impregnation and calcination process were around $400 \mathrm{~nm}$ in diameter. Moreover, the electrode prepared via electrodeposition showed higher activity toward the dechlorination of chloroacetic acids than the electrode prepared via the chemical reduction process. Zhang et al. [93] deposited Au NPs on glassy carbon electrode by potentiostatic technique at $-0.4 \mathrm{~V} / \mathrm{SCE}$ for $600 \mathrm{~s}$. Homogenous Au NPs covered the modified glassy carbon with a mean size of about $40 \mathrm{~nm}$. Electrodeposition has also been used to synthesize NPs on porous supports. For example, Li et al. [60] successfully deposited Pd NPs onto $\mathrm{Ni}$ foam in an aqueous solution composed of $1 \mathrm{mmol} \mathrm{L}^{-1}$ of $\mathrm{PdCl}_{2}$ and $3 \mathrm{mmol} \mathrm{L}^{-1}$ of $\mathrm{NaCl}$ with a fixed current of $6 \mathrm{~mA}$ at $40^{\circ} \mathrm{C}$ for $2 \mathrm{~h}$.

\section{Pulsed electrodeposition}

During the electrodeposition process, the mass transfer of metal ions is the limiting step so that regular current pulses are used to allow a sufficient concentration of metal ions to diffuse towards the support. As a result, the pulsed electrodeposition method has been recently investigated for NPs synthesis. Pulse electrodeposition provides an excellent control of the noble metal loading by forming nanocrystalline deposits with finer grains and a more compact structure in comparison with NPs from galvanostatic electrodeposition $[29,36,91]$. The process can be divided into two steps: 
(1) The first step consists in a constant current applied for a short time to produce nanoparticle nuclei. The concentration of metal ions close to the electrode drops because the electrochemical reaction is much faster than metal ions transfer during this pulse time.

(2) Then a relaxation step is necessary for ions to diffuse close to the support surface where the species reduction occurs [95]. The relaxation step takes more time than the nuclei creation process to get enough metal ions in the vicinity of the support surface.

The short current applied process followed by a relaxation period is typically repeated thousands of times until the desired loading of nanoparticles is achieved.

The NPs originated from pulse electrodeposition are small with a more substantial number of low-coordinated (edge/corner) sites, which facilitates the catalytic activity and enhances the electrocatalytic dechlorination performance [96]. He et al. [96] and Sun et al. [97] found that NPs of Pd originating from pulse electrodeposition favor the generation and stabilization of chemisorbed active hydrogen owing to their high amount of exposed (111) facets. Moreover, Pd NPs-modified Ni foams obtained by pulse electrodeposition have higher specific surface area and larger reaction contact sites for dechlorination process in comparison with chemical-deposited $\mathrm{Pd} \mathrm{Ni}$ foams.

Furthermore, an improved pulsed electrodeposition process known as double-step potential deposition, has been developed allowing a better control over the dimension and dispersion of metal NPs. This consists of independent nucleation and growing steps [43, 47]. The suitable potentials for catalytic metal nucleation and growth are determined by cyclic voltammetry as shown in Fig. 5. The nucleation process is performed at sufficiently negative potential $\left(E_{n}\right)$ so that the deposition process is limited by the diffusion of the species. As a result, instantaneous nucleation of metal takes place. The second step consists in the growing process. The potential is fixed at the reduction potential of the metal $\left(\mathrm{E}_{\mathrm{g}}\right)$. By this way, the deposition process is kinetically-controlled to ensure that nucleation of new sites no longer occurs. The nucleation time should be short in order to avoid excessive production of NPs, while the growth occurs over a longer duration to guarantee the sufficient growth of NPs. The nanoparticle size can be controlled via the deposition time in the second step. $\mathrm{Cu}$ NPs electrodes with an average dimension of 20-30 $\mathrm{nm}$ have been obtained from the above process. The modified electrode exhibited remarkable electrocatalytic properties for the reductive dehalogenation reaction. The reduction peak potentials recorded at $\mathrm{Cu}$ NPs electrodes at $v$ $=0.2 \mathrm{~V} \mathrm{~s}^{-1}$ were positively shifted by $0.3-0.5 \mathrm{~V} / \mathrm{SCE}$ compared with the reduction potentials measured at a non-catalytic electrode such as glassy carbon. 

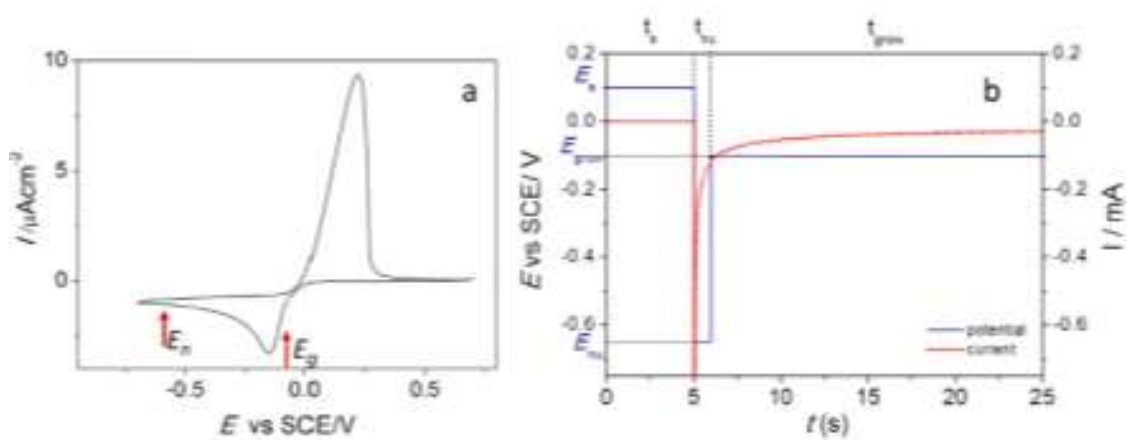

Fig. 5 (a) Cyclic voltammetry in $\mathrm{H}_{2} \mathrm{O}+5 \mathrm{mM} \mathrm{CuSO}_{4}+0.1 \mathrm{M} \mathrm{LiClO}_{4}$ at GC, scan rate 0.2 $\mathrm{v} \mathrm{s}^{-1}$; (b) Double potential pulse for the $\mathrm{Cu}$ deposition applied in this study [43].

\subsubsection{Multi-metal NPs}

Recently, increasing attention has been paid to bi- and tri-metallic NPs to obtain higher electrocatalytic property, resulting from the synergistic reaction between metals [98-100]. The route of multi-metal NPs formation can be classified into (1) simultaneous way or (2) successive way.

The simultaneous formation route consists in developing the multi-metallic NPs following a one-step reduction. Bimetallic $\mathrm{Co}_{x} \mathrm{Ni}_{1-\mathrm{x}}$ (with $\mathrm{x}=0,0.1,0.3,0.5,0.7,0.9,1$ ) NPs have been prepared by this method [82]. Sun et al. [101] have also simultaneously deposited Pd-Ni bimetallic NPs onto Ti mesh by applying a current of $3.75 \mathrm{~mA} \mathrm{~cm}$ for $50 \mathrm{~min}$. Actually, it is not easy to reduce two or more kind of metal ions into multimetallic NPs by electrochemical reduction, due to the difference of electron-capture ability of metal ions. To circumvent this problem, the successive way which consists in a sequential immobilization of NPs has been proposed. NPs of the first metal are first formed, and the second metal is subsequently introduced. The galvanic replacement reaction is often used to introduce the second metal. Thus, Peng et al. [32] successfully synthesized $\mathrm{Pd}-\mathrm{Fe} / \mathrm{Ni}$ electrode via cathodic electrodeposition of Fe NPs on Ni foam, followed by spontaneous deposition of Pd NPs. The galvanic replacement reaction took place on both $\mathrm{Fe}$ and $\mathrm{Ni}$. Durante et al. [43] produced $\mathrm{Ag} / \mathrm{Cu}$ NPs by electroless displacement deposition onto $\mathrm{Cu}$ NPs-modified glassy carbon (average diameter of 20-30 $\mathrm{nm})$, giving a $\mathrm{Cu}$-nanostructured glassy carbon decorated with very small Ag NPs. Underpotential deposition (UPD) has also been considered to introduce the second metal in the fabrication of bimetallic nanomaterials [102]. This phenomenon can occur when a metal is deposited on another material at a potential more positive than the Nernst potential of the metal substrate. It allows the formation of a monolayer or submonolayer of a foreign metal onto the substrate surface, thus avoiding the deposition of the metal on itself (bulk deposition) (Fig. 6) [93, 103]. Such phenomenon allows precise and reproducible control of the amount of the foreign metal ad-atoms on the substrate. For 
example, Zhang et al. [93] first deposited a monolayer of $\mathrm{Pb}$ onto $\mathrm{Au}$ NPs modified glassy carbon by means of potentiostatic polarization at a designated UPD potential $(-0.25 \mathrm{~V}$ vs. $\mathrm{Ag} / \mathrm{AgCl})$. Then spontaneous deposition of $\mathrm{Ag}$ NPs was performed, obtaining a mean NPs size of $30 \mathrm{~nm}$ by galvanic replacement of the Pb UPD monolayer in a Ag nitrate solution. Yu et al. [103] also developed a decorated Pt@Au NPs catalyst on glassy carbon synthesized by $\mathrm{Cu}$ underpotential deposition and $\mathrm{Pt}$ redox replacement. It is interesting to note that in addition to the synergistic effect of multi-metal, the catalytic efficiency is also improved thanks to the increase of the surface area after the second metal deposition [43].

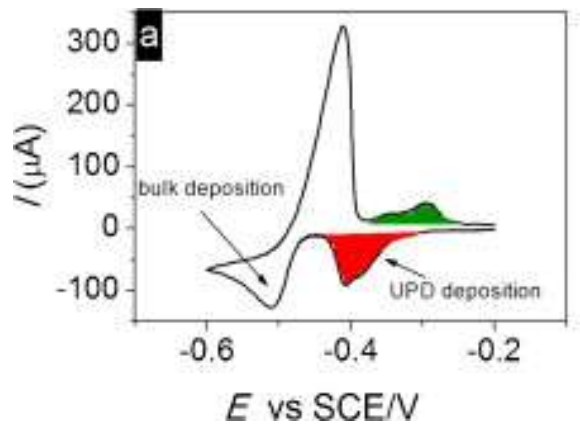

Fig. 6 Cyclic voltammetry of $\mathrm{Pb}\left(\mathrm{NO}_{3}\right)_{2} 2 \mathrm{mM}$ in $\mathrm{H}_{2} \mathrm{O}+0.1 \mathrm{M} \mathrm{HClO}_{4}$ at $\mathrm{Ag} 600 @ \mathrm{CuNPs}-$ GC, scan rate $0.2 \mathrm{~V} / \mathrm{s}$ [43].

\subsubsection{New methods for the deposition process}

Some methods have been used to improve the spontaneous deposition reaction, including ultrasonication, photocatalysis and addition of surfactants:

(1) Ultrasonication

Ultrasonication can enhance mass transfer of metal ions and improve the homogeneity of the metal deposition into porous electrode materials [104]. In addition, ultrasonication can trigger acoustic cavitation, initiating and enhancing the chemical activity of reacting sites and mass transport of liquid to the surface of the electrode substrate [105]. Cavitation phenomenon induced by ultrasonic irradiation creates hot spots with high temperature and pressure at the liquid-solid interface. This may lead to an increased number of nucleation and crystallization centers at the surface of the electrode, as well as a higher rate of noble metal ion reduction to the metallic state. Macijauskienè and Griškonis [106] reported that the size of nanocrystalline Ag on the surface of graphite felt can be reduced from approximately $14 \mathrm{~nm}$ to $11 \mathrm{~nm}$ with the presence of ultrasound action during the deposition process. Moreover, the mass fraction of electroless-deposited $\mathrm{Ag}$ on the graphite felt in the presence of ultrasound action is 1.6 times higher than that of graphite felt modified without ultrasound action. However, Simonet et al. [30] found that 
short time (within 1 minute) sonication procedure had no significant influence on nanoparticle deposition onto flat electrode supports.

(2) Addition of surfactants

Another method used to improve nanoparticles deposition is the use of surfactants. The most common surfactants are poly-( $N$-vinyl-2-pyrrolidone) (PVP, MW-10000) [107-109], sodium carboxymethylcellulose (CMC) [110], cetyltrimethylammonium bromide (CTAB) cetyltrimethylammonium chloride (CTAC) $[41,107,111]$. They play a key role in the physical separation of the NPs and in the inhibition of their agglomeration [88]. PVP is one of the most used polymers since it has a high-quality stability for promoting the formation of well-defined NPs [108, 112, 113]. Indeed, PVP has long chains that can prevent nanoparticle clusters from nucleating on the surface. As a result, PVP can allow the formation of monodisperse NPs. Uberman et al. [88] have shown that Pd NPs stabilized with PVP exhibited high stability; the colloidal dispersion can be preserved for several months without the appearance of any precipitate. Furthermore, PVP molecules avoid the oxidation of Pd NPs at air, which occurs with metallic Pd. The comparison of the catalytic activity of different Ag NPs modified Ni foams toward the reductive dechlorination of alachlor has been performed [87]. A 21\% higher conversion has been obtained when the NPs deposition was performed in the presence of PVP. This higher catalytic efficiency could be due to a higher surface area of the PVP NPs-modified foams. Liu et al. [90] also proved that PVP is the crucial factor in forming the optimised Ag dendrites since PVP has a structure-directing effect during the deposition process. It has been shown that conductive polymers, including polypyrrole, polyaniline, and polythiophene electrodeposited on the electrode substrate were also able to disperse the NPs and improve the electronic properties of the electrode, leading to an enhancement of the catalytic performances [114]. Finally, other platforms can be used to stabilize the NPs formed, such as silica matrices which can help control NPs architecture and electrochemical behavior [115].

\section{(3) Mediated electrosynthesis}

The preparation of metallic (Ag, $\mathrm{Rh}, \mathrm{Pd}, \mathrm{Au})$ and bimetallic $\left(\mathrm{RhPd}, \mathrm{PdAg}, \mathrm{Au} / \mathrm{Cu}_{2} \mathrm{O}\right) \mathrm{NPs}$ can also be achieved by mediated electrosynthesis [41, 107, 108, 111, 116]. In this case, the electrode potential applied corresponds to the redox potential of the mediator which is not consumed during the reaction. Various mediators have been reported for the synthesis of NPs, such as molecular oxygen [116], methylviologen [107, 111], or benzimidazo[1',2':1,2]quinolino[4,3-b][1,2,5]oxodiazolo[3,4-f]quinoxaline (BIQOQ) [108]. The mediated electrochemical synthesis requires catalytic amounts of nonconsumable mediator (no waste generated), which makes it more environmentally attractive than chemical synthesis. In addition, it allows the production of "ultra small" 
NPs $(<10 \mathrm{~nm})$ that offer undeniable advantages for various applications [41]. However, due to the utilization of redox mediators, the NPs are synthetized in the bulk solution and not directly deposited onto the electrode surface. Therefore to date, and to the best of the authors' knowledge, this method has not yet been used for electrocatalytic reduction of halogenated organic compounds applications.

\section{Characterization of the NPs modified porous electrode}

\subsection{Surface area}

The electrocatalytic ability is closely linked to the surface area of the electrode. Indeed, a higher surface area of the support implies more catalytic sites for the reductive dehalogenation of organic halides. For this reason, the determination of the surface area of both electrode substrate and NPs is critical.

\subsubsection{Nanoparticle surface area}

It can be insightful to determine the surface area of immobilized NPs without the support since they are the center of the catalytic activity. Nanoparticle surface area is related to particle size and shape. There are several common methods allowing a rough estimation of NPs surface area:

(1) Scherrer estimation

X-ray diffractograms can be recorded to approximate the surface area of NPs. According to the method of Williamson and Hall [117], the average particle size can be calculated from the broadening ( $\left.\beta_{1 / 2}\right)$ of XRD peaks, given by the Scherrer formula (Eq. 3).

$\mathrm{d}=\frac{k \lambda}{\beta_{\overline{1}} \cos (\theta)}$

Where $d$ is the average particle size (its diameter if we consider it as a sphere) (nm), $\lambda$ the wave-length of X-ray radiation (1.54 $\AA$ ), $\theta$ the angle at the position of the peak maximum, $\beta_{\frac{1}{2}}$ the width (in radians) of the diffraction peak at half height, and $k$ a dimensionless shape factor, close to 0.9 but which varies with the actual shape of the crystallite.

The total surface area of an assembly of spherical particles with diameter $d$ and density $\rho$, is given by Eq. 4 [87, 118]:

$\mathrm{S}=\frac{6000}{\rho d}$

Which $\mathrm{S}\left(\mathrm{m}^{2} \mathrm{~g}^{-1}\right), \rho$ the metal catalyst density $\left(\mathrm{g} \mathrm{cm}^{-3}\right)$ and $\mathrm{d}(\mathrm{nm})$

(2) UPD 
$\mathrm{Pb}, \mathrm{Cd}$ and $\mathrm{Ti}$ are known to form a UPD monolayer on many noble metals [43]. The method to calculate the total surface area of NPs (A) consists in the deposition of lead onto the electrode surface by UPD and then the estimation of the surface area using the following equation (5):

$\mathrm{A}=\frac{\mathrm{Q}_{\mathrm{UPD}}}{\mathrm{q}_{\mathrm{m}}}$

Where QUPD $(\mathrm{C})$ is the charge consumed to reduce the metal, obtained by integrating the current density against time using either cyclic voltammetry or anodic stripping curves, and $\mathrm{q}_{\mathrm{m}}$ the monolayer charge density that is $0.390 \mathrm{mC} \mathrm{cm}^{-2}$ for $\mathrm{Pb}$ [119]. The electrochemical underpotential and bulk deposition of lead and cadmium on silver macroelectrodes and AgNP arrays composed of varying sizes of particles has been investigated by Campbell and Compton [119]. They pointed out that a minimum diameter of ca. $50 \mathrm{~nm}$ is required in order to clearly observe the underpotential deposition and the corresponding stripping processes for both $\mathrm{Pb}$ and Cd. Singh and Buttry [120] successfully measured the electroactive area of catalyst available for the oxygen reduction using the charge for the UPD of $\mathrm{Pb}$ on the $\mathrm{Ag}$ NPs. Verlato et al. [87] also used this method to estimate the total Ag surface area of Ag NPs-modified Ni foam. However, they also showed that the value was overestimated because the galvanic displacement reaction of lead onto $\mathrm{Ni}$ foam also occurred leading to an amplification of the signal. They concluded that this method is not suitable to assess the Ag surface area in Ag-Ni samples.

\section{(3) Gas desorption}

The coulombic charge for gas desorption $\left(\mathrm{Q}_{\mathrm{gas}}\right)$, including $\mathrm{H}_{2}[121,122]$ or $\mathrm{CO}[123]$ on the electrode can be used to approximate the surface area of the target electrodes. The electrochemically active surface area can be calculated using the following equation (7):

$\mathrm{S}=\frac{\mathrm{Q}_{\text {gas }}}{[\mathrm{M}] \times \mathrm{k}}$

Where $\mathrm{Q}_{\text {gas }}$ is the $\mathrm{H}_{2}$ or $\mathrm{CO}$ desorption charge measured with the electrode substrate, $\mathrm{mC}$ $\mathrm{cm}^{-2} ;[\mathrm{M}]$ represents the metal catalyst loading on the electrode, $\mathrm{mg} \mathrm{cm}^{-2} ; \mathrm{k}$ represents the charge needed to oxidize a monolayer of $\mathrm{H}_{2}$ on the metal. For example, the charges for a monolayer of $\mathrm{H}_{2}$ oxidized on $\mathrm{Pt}$ and $\mathrm{Pd}$ is $0.21 \mathrm{mC} \mathrm{cm}^{-2}$ [124]. And for $\mathrm{CO}, \mathrm{k}$ is 0.484 $\mathrm{mC} \mathrm{cm}{ }^{-2}$ on Pt (102).

\subsubsection{Support surface area}

Three types of surface areas can be considered for the support: i) the geometric surface area which is usually applied to plane electrodes, ii) the BET surface area which is typically used for the 3-dimensional electrodes and iii) the active electrochemical surface 
area, which is associated to the surface area that is electrochemically accessible. The geometric surface cannot be used with 3-dimensional porous electrodes as it will give an underestimated value. The BET method is a classical technique to determine the specific surface area of porous materials and is suitable to characterize 3-D electrodes. However, since nitrogen is the most commonly used gaseous adsorbate for specific surface area measurement by BET methods, it gives an overestimation of the active surface area in aqueous medium. Indeed, owing to its low size, nitrogen can penetrate pores that are not accessible to water. Thus, organic molecules cannot go through tiny pores, even if they contain catalytic sites.

The electrochemically measured surface area is a good method to estimate the surface area accessible to electroactive species. Different electrochemical methods can be used to measure it, and four of them are described thereafter:

(1) Cyclic voltammetry by varying the scan rate in the presence of a redox probe such as potassium ferricyanide $\left(\mathrm{K}_{3}\left[\mathrm{Fe}(\mathrm{CN})_{6}\right], 1 \mathrm{mM}\right)$ can be used to estimate the electrode surface using the Randles-Sevcik equation for a one-electron process [81, 125]:

$\mathrm{I}_{\mathrm{p}}=0.446 \mathrm{FSC}_{0} \sqrt{\mathrm{D}_{0}} \sqrt{\frac{\mathrm{F}}{\mathrm{RT}}} \sqrt{\mathrm{V}}$

with, $\mathrm{I}_{\mathrm{p}}$, oxidation peak current, A; F, Faraday constant, $96485 \mathrm{C} / \mathrm{mol}$; S, electrode surface, $\mathrm{cm}^{2} ; \mathrm{D}_{0}$, diffusion constant, $0,76 \times 10^{-5} \mathrm{~cm}^{2} \mathrm{~s}^{-1}$ in $0.1 \mathrm{~mol} \mathrm{~L} \mathrm{~L}^{-1} \mathrm{KCl} ; \mathrm{C}_{0}$, concentration of $\mathrm{Fe}(\mathrm{CN})_{6}{ }^{3-}, \mathrm{mol} \mathrm{cm}{ }^{-3} ; \mathrm{R}, 8.14 \mathrm{~J} \mathrm{~mol}^{-1} \mathrm{~K}^{-1}$; T, Kelvin temperature, $\mathrm{K} ; \mathrm{v}$, scan rate, $\mathrm{V} \mathrm{s}^{-1}$.

For a constant concentration of the redox probe, the increase of peak currents can be ascribed to an increase of the electrochemically active surface area. A linear regression curve can be fitted to the $\mathrm{I}_{\mathrm{p}} v s \sqrt{\mathrm{v}}$ plot, and $\mathrm{S}$ being obtained from the slope of the curve.

(2) UPD can be also used to measure support surface area by covering a metallic monolayer on all the support surface, instead of nanoparticle surface. The support should be a metallic substrate, such as Ni foam, Fe foam, and Ti mesh [87].

(3) Impedance measurements aim at evaluating the capacity of electrode samples and, therefore, their surface area. The specific surface area $\left(\mathrm{cm}^{-1}\right)$ is calculated as:

$\mathrm{S}_{\text {foam }}=\frac{\mathrm{C}_{\text {foam }}}{\mathrm{C}_{\text {sheet }}}$

Where the capacity $\mathrm{C}_{\text {foam }}$, expressed in $\mathrm{F} \mathrm{cm}^{-3}$, refers to a foam volume and the capacity $\mathrm{C}_{\text {sheet }}$, expressed in $\mathrm{F} \mathrm{cm}^{-2}$, refers to a sheet area. Equation (8) assumes that the sheet is perfectly smooth, and thus may underestimate the surface area of the foams, to some extent [63]. 
(4) In the specific case of $\mathrm{Ni}$ foam, the electrochemical surface area can be estimated by peak integration of the quasi-reversible system corresponding to the couple Nickel hydroxide/nickel oxihydroxide $\left(\mathrm{Ni}(\mathrm{OH})_{2} / \mathrm{NiOOH}\right)$, using equation (9).

$S_{\text {foam }}=\frac{Q_{\text {foam }}}{Q_{\text {sheet }}}$

Where $\mathrm{Q}_{\text {foam }}$ is the peak integration for $\mathrm{Ni}$ foam, peak area in the cyclic voltammetric spectra and $\mathrm{Q}_{\text {sheet }}$ is the peak integration for $\mathrm{Ni}$ sheet, peak area in the cyclic voltammetric spectra. An example is given in Fig. 7.

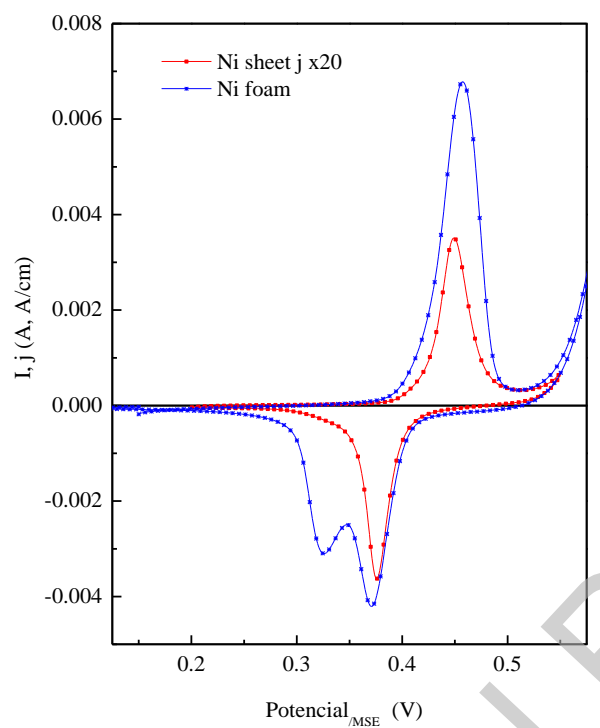

Fig. 7. Cyclic voltammetry of $\mathrm{Ni}$ foam and $\mathrm{Ni}$ sheet in $1.0 \mathrm{~mol} \mathrm{~L}^{-1} \mathrm{KOH}$.

\subsection{Other characteristics}

\subsubsection{Nanoparticle size and shape}

It is well known that the metal catalytic activity is strongly dependent on the particle shape and size. NPs size can significantly affect the electrocatalytic process, a higher surface area-to-volume ratio being associated with more exposed active sites for lower particle sizes [126]. The options to measure the particle size on electrode surface include, scanning electron microscopy (SEM), transmission electron microscopy (TEM), atomic force microscopy (AFM), and X-ray diffraction analysis (XRD) (Table 1). As previously explained, equation (3) is used to calculate the average crystallite size by XRD. The particle size distribution can be estimated by imaging methods such as SEM or TEM analyses [127]. The association of imaging methods with XRD can be particularly useful, as reported in the work of Bansal et al. [127], where the authors could correlate the shape of Ag NPs with their crystallinity. They found that (100) plane predominates in the case of nanocubes, whereas nano-spheres show a mixture of (111) and (100) planes with a 
similar intensity in the (111) reflection as seen for nanoprisms. The authors also correlated the catalytic activity of the material with its cristallinity and found that for the oxidation of formaldehyde, a nanomaterial rich in (111) facets, as it is the case for nanoprisms and nanospheres, is more active than a nanomaterial rich in (100) facets.

\subsubsection{Metal loading}

The noble metal loading can be determined by the decrease in the concentration of dissolved noble metal ions caused by the deposition, or directly by measuring metal ions previously re-dissolved in acidic solution. The common technologies are listed in Table 1. For example, UV visible spectroscopy has been used to calculate Pd loading, measuring the remaining concentration of $\mathrm{PdCl}_{2}$ in solution during spontaneous deposition [128]. To measure the concentration of ions after metal dissolution, inductively coupled plasmamass spectrometry (ICP-MS) is usually used. Linear sweep voltammetry (LSV) with a rotating disc electrode can also be applied to measure the dissolved metal ions concentration. Thus, Verlato et al. [87] established a calibration curve by LSV (Fig. 14) to determine the concentration of $\mathrm{Ag}$ cations from a solution previously prepared by heating at $80^{\circ} \mathrm{C} \mathrm{a} \mathrm{Ag-modified} \mathrm{Ni}$ foam in $5 \mathrm{MHNO}_{3}$. The measured $\mathrm{Ag}^{+}$concentrations were in agreement within $5 \%$ with those determined by ICP-MS.

X-ray photoelectron spectroscopy (XPS) and energy-dispersive spectroscopy (EDS) can roughly provide composition information of NPs. EDS is commonly used to determine the weight percent and atomic percent of NPs. XPS is used to estimate the composition of the NPs surface. For example, Li et al. [60] determined that the Pd NPs of a palladium/polypyrrole/foam nickel electrode mainly existed as metallic $\mathrm{Pd}$ according to the binding energies of the major spin-orbit split doublet of $\mathrm{Pd}\left(\mathrm{Pd} 3 \mathrm{~d}_{5 / 2}\right.$ and $\left.\mathrm{Pd} 3 \mathrm{~d}_{3 / 2}\right)$ at 335.3 and $340.8 \mathrm{eV}$, respectively. They also estimated the atomic concentration of $\mathrm{Pd}$ to be $1.21 \%$. During the characterization of nitrogen-doped glassy carbon supports with electrodeposited Pd NPs, Perini et al. [47] determined an overall surface stoichiometry of $\mathrm{C}_{0.85} \mathrm{~N}_{0.15}$ from the analysis of $\mathrm{N} 1 \mathrm{~s}$ and $\mathrm{C} 1 \mathrm{~s}$ XPS peaks. Thanks to the high sensitivity of XPS, low content species can be detected and their oxidation state determined, as for example $\mathrm{Pd}(\mathrm{II})$ found on Pd NPs previously used for a dechlorination process [94]. 
Table 1 Common technologies used for the characterisation of metallic NPs modified electrodes

\begin{tabular}{|c|c|c|c|}
\hline Tech. & Description & Figure illustration & Ref. \\
\hline \multicolumn{4}{|c|}{ NPs size and shape } \\
\hline SEM & $\begin{array}{l}\text { High resolution 2-dimensional images of particles and support surface, } \\
\text { particle size distribution, shape. }\end{array}$ & & [35] \\
\hline \multirow[t]{2}{*}{ TEM } & $\begin{array}{l}\text { Particle size distribution, shape, surface texture. } \\
\text { Higher resolution than SEM. }\end{array}$ & & {$[60]$} \\
\hline & & $\begin{array}{l}\text { Fig. 9. TEM images of Pd NPs on Pd/PPY(PTS)/Ni electrode. } \\
\text { Insets show its corresponding selected area by electron } \\
\text { diffraction and high resolution transmission electron } \\
\text { microscopy image. }\end{array}$ & \\
\hline \multirow[t]{2}{*}{ AFM } & $\begin{array}{l}\text { Offers three-dimensional visualization of NPs distributed on a flat surface by } \\
\text { measuring the small force between a sharp probe. With the appropriate } \\
\text { protocols, it can provide information about nanoparticle size, shape, surface } \\
\text { texture, and roughness. }\end{array}$ & : & [129] \\
\hline & It lacks the intrinsic structural sensitivity of electron microscopies. & 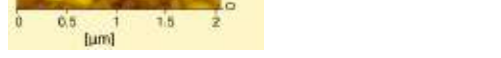 & \\
\hline
\end{tabular}


Identification of crystal structure by the constructive interference of monochromatic X-ray and a crystalline sample.

XRD

Determination of crystallite size from the most intense peaks of the XRD patterns according to the Scherrer formula, Equation (3).

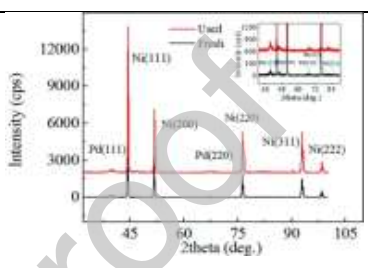

Fig. 11. XRD patterns of the fresh Pd/PPY(PTS)/Ni electrode and used electrode for five times.

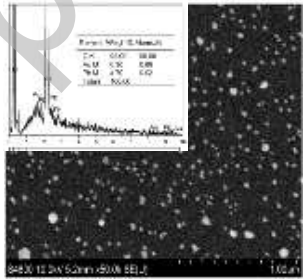

Fig. 12. SEM and EDS analysis of the $\mathrm{Pb} / \mathrm{Au} / \mathrm{GC}$

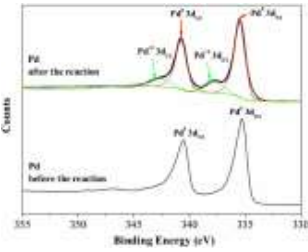

Fig. 13. XPS spectra of Pd on the Pd/Fe-C electrode befor and after the dechlorination reaction
Being quantified to provide additional semi-quantitative elemental analysis. Offering far greater surface sensitivity than EDS.

To provide overall elemental composition, EDS is commonly coupled with SEM or TEM, where an electron beam scans the surface of the sample and Closely spaced lines may not be resolved due to poor energy resolution of the detector 
Determination of the overall elemental composition after sample dissolution by acid.

LSV

Determining the concentration according to the value of the limiting current

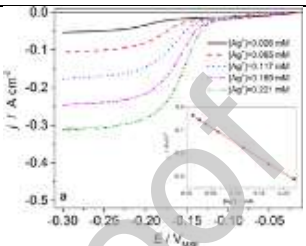

[87]

Fig. 14. LSV recorded with an Au rotating disc electrode
$\left(2000 \mathrm{~min}^{-1}\right)$. The inset shows the limiting current $-\left[\mathrm{Ag}^{+}\right]$ dependence (calibration curve)

ICP-MS Based on the determination of the total elemental concentration in nanoparticle suspension after sample dissolution by acid.

Scanning electron microscopy (SEM), transmission electron microscopy (TEM), atomic force microscopy (AFM), X-ray diffraction (XRD), energy-dispersive spectroscopy (EDS), X-ray photoelectron spectroscopy (XPS), linear sweep voltammetry (LSV), inductively couple plasma mass spectrometry (ICP-MS). 


\section{Influence of the electrode materials on the reductive dehalogenation process}

The mechanism of dehalogenation depends on the nature of the electrode material, the target organic halide, the solvent and the proton availability in the reaction medium. Glassy carbon (GC) electrode is often used as a reference since it is an inert electrode, considered as an outer-sphere electron donor pertaining to a non-catalytic system [131]. The difference between the reduction peak potential of organic halides on the metal and that on glassy carbon $E_{p}(M)-E_{p}(G C)$ has been used as diagnostic criterion to measure the electrocatalytic ability of some metal catalysts in organic media. The higher the value of $E_{p}(M)-E_{p}(G C)$, the greater the catalytic activity of the metal. Based on this criterion, Fig. 15 was deduced from recent decade literature $[5,34,47,86,131-136]$. We can notice that:

(1) Ag is the most efficient catalytic cathode material for dehalogenation process in organic medium, leading to a high positive shift of the potential; the relevant $E_{p}(M)-E_{p}(G C)$ values ranging from 0.2 to $1.3 \mathrm{~V}$;

(2) Both $\mathrm{Cu}$ and $\mathrm{Au}$, which belong to the same column of the periodic table as Ag, exhibit good catalytic activities with $\mathrm{E}_{\mathrm{p}}(\mathrm{M})-\mathrm{E}_{\mathrm{p}}(\mathrm{GC})$ values from 0.03 to $0.99 \mathrm{~V} / \mathrm{SCE}$ and from 0.2 to $0.81 \mathrm{~V} / \mathrm{SCE}$, respectively;

(3) $P d$ is the second best catalyst next to $A g$ in organic medium with $E_{p}(M)-E_{p}(G C)$ values ranging from 0.28 to $1.18 \mathrm{~V} / \mathrm{SCE}$. It is important to remind that these analyses were performed in organic medium. Hydrodehalogenation of organic halides on $\mathrm{Pd}$ in aqueous medium is well-known as a very efficient dehalogenation process. Detailed discussion is given in section 4.2 .

(4) $\mathrm{Pb}, \mathrm{Ni}$ and $\mathrm{Pt}$ display also good catalytic activity, with $\mathrm{E}_{\mathrm{p}}(\mathrm{M})-\mathrm{E}_{\mathrm{p}}(\mathrm{GC})$ values ranging from 0.3 to $0.7 \mathrm{~V} / \mathrm{SCE}$;

(5) The lowest catalytic activities are found for mercury, Fe and zinc with the smallest $E_{p}(M)$ $\mathrm{E}_{\mathrm{p}}(\mathrm{GC})$ values (from 0.2 to $0.5 \mathrm{~V} / \mathrm{SCE}$ ). 


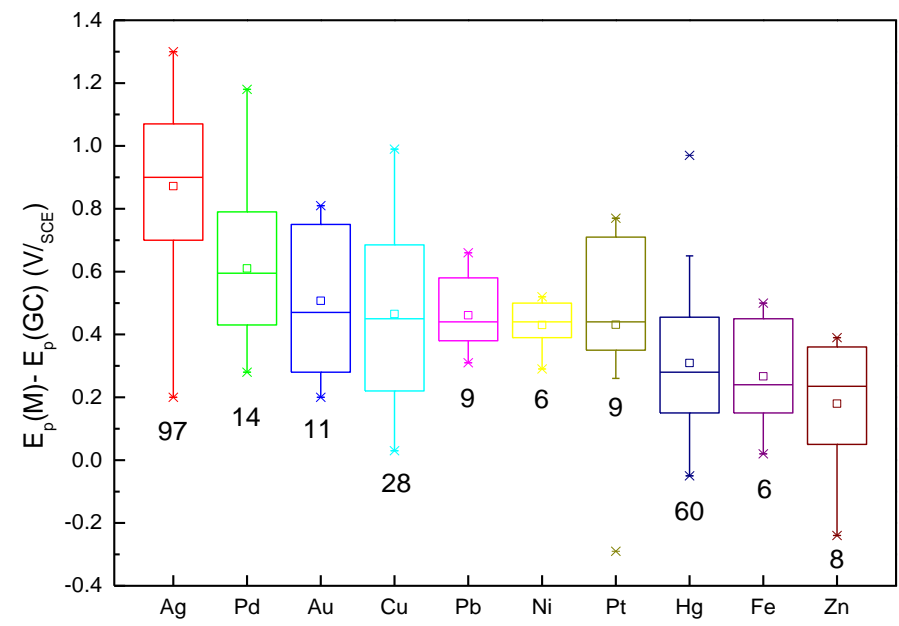

Fig. 15. The experimental electrocatalytic activity scale (against the non-catalytic glassy carbon) of the tested metals toward the reduction of organic halides in organic medium. The numerals below the box show the number of data used for each metal. (The horizontal black line in the box represents the median value, the low and upper edges of the box mark the 25th and 75th percentiles, respectively; the little box marks the average value; and the extension lines from the box show the highest and lowest values, stars mark outlier) $[5,34,47,86,131$ 136].

In the next sections, we focus on the $\mathrm{Ag}, \mathrm{Pd}$, and $\mathrm{Cu}$ electrode materials, which have been extensively studied for dehalogenation reaction. Since the mechanisms involved in reductive dehalogenation process have been recently reviewed [137, 138], we will more focus this part on the performances of each electrode material for the reduction of halogenated POPs.

\subsection{Ag}

The mechanism of dehalogenation on silver has been widely investigated in organic media. It is known to proceed via an adsorption step of the halogenated compound "RX" on the surface of the electrode leading to an "attenuated radical" intermediate of the kind $\mathrm{R} \cdots \mathrm{X} \cdots \mathrm{Ag}$, which is responsible for its remarkable electrocatalytic ability [139]. Indeed, Ag allows a dramatic decrease in the bond dissociation energy of carbon and halide, leading to a significant positive shift of the reduction potential with greater current density than at GC [132, 139, 140]. The catalytic ability of Ag towards organic halides is based on dissociative electron transfer (DET) process. DET is a mechanism (equation (9-12)) that occurs for the scission of carbon-halogen bonds during the reduction of organic halides on inert electrodes, such as glassy carbon [141]. There are two possible ways for the DET mechanism, including a "stepwise way" with the formation of an intermediate radical anion $R X^{\cdot-}$ (equations (9) and (10)) or a "concerted way" leading to the formation of a radical $\mathrm{R}^{\bullet}$ and an anion $\mathrm{X}^{-}$(equation (11)). The radical $\mathrm{R}^{\bullet}$ is usually easier to reduce than the corresponding organic halide molecule so that a two-electron wave is observed. The formation of the transient $R X^{\cdot-}$ based on $1 \mathrm{e}^{-}$addition and the cleavage step can be seen as an intramolecular DET.

$\mathrm{RX}+\mathrm{e}^{-} \leftrightarrow R X^{\cdot-}$ 


$$
\begin{aligned}
& R X^{\bullet^{-}} \leftrightarrow R^{\bullet}+X^{-} \\
& R X+\mathrm{e}^{-} \leftrightarrow R^{\bullet}+X^{-} \\
& R^{\bullet}+\mathrm{e}^{-} \leftrightarrow R^{-}
\end{aligned}
$$

A catalytic effect of $\mathrm{Ag}$ toward the reduction of $\mathrm{C}-\mathrm{Cl}$ bound takes place only when the concerted mechanism prevails (equation 11) [142]. In opposite, when a stepwise DET mechanism happens, the catalytic effect of Ag cannot be observed. For example, the reduction of aromatic and heteroaromatic compounds 1-6 (Scheme (1)) that follow the stepwise mechanism owing to their low lying $\pi^{*}$ orbitals favoring the formation of transient $\mathrm{RX}^{-}$, is little affected by the nature of the electrode material [141]. Thus, for these compounds, Ag electrode acts as a non-catalytic electrode, like glassy carbon. In such case, the electrode serves as an outer-sphere electron transfer donor. These results cannot be extended to organic bromides and iodides owing to the high affinity of $\mathrm{Ag}$ with these compounds. For aromatic bromides, a change of mechanism from stepwise to concerted mechanism occurs on passage from an outer-sphere electron donor electrode such as GC to Ag [143].

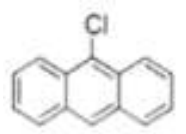

1

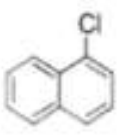

2

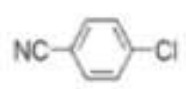

3

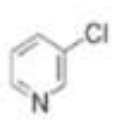

4

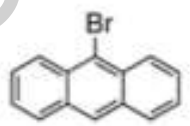

6

Scheme (1): Aromatic and heteroaromatic compounds involving a stepwise DET mechanism

A diagnostic measurement for distinguishing the stepwise or concerted mechanism is the determination of the electron transfer coefficient $\alpha$ [141]. In the concerted mechanism, the heterogeneous electron transfer is the rate determining step (equation (11)), and $\alpha$ is usually very small $\alpha \ll 0.5$ (generally around 0.3 ). In the stepwise mechanism, $\alpha$ closes to 0.5 is expected. The transfer coefficient $\alpha$ can be estimated from cyclic voltammetry according to equations (13) and (14) [144]. $\alpha$ can be determined by the dependence of $E_{p}$ on $\log (v)$ (equation (9)) and the values of half peak width, $\mathrm{E}_{\mathrm{p} / 2}-\mathrm{E}_{\mathrm{p}}$ (equation (14)).

$\frac{\partial E_{p}}{\partial \log v}=-\frac{1.151 R T}{\alpha F} \cdots$
$E_{p / 2}-E_{p}=\frac{1.857 R T}{\alpha F}$

Where $E_{p}$ is the reduction peak potential, $\mathrm{V} ; \mathrm{E}_{\mathrm{p} / 2}$ is the potential at half peak, $\mathrm{V} ; \mathrm{R}$ is the molar gas constant, $8.314 \mathrm{~J}(\mathrm{~mol} \cdot \mathrm{K})^{-1}$; $\mathrm{T}$ is the temperature, $\mathrm{K}$; $\mathrm{F}$ is the Faraday constant $96485 \mathrm{C} \mathrm{mol}^{-1} ; v$ is the scan rate, $\mathrm{V} \mathrm{s}^{-1} ; \alpha$ is the electron transfer coefficient.

A mechanism has been proposed by Isse et al. to explain the interaction between $\mathrm{Ag}$ and the chlorinated compounds [143]. The authors suggest that the strong interaction of $\mathrm{RCl}$ with $\mathrm{Ag}$ decreases the activation energy of the concerted DET process with respect to the outer sphere electron transfer path (Fig. 16). Thus, the kinetics of the reaction is improved as the $\mathrm{C}-\mathrm{Cl}$ bond is considerably weakened owing to the $\mathrm{Cl}$...Ag and $\mathrm{R}$...Ag interactions. 
(a)

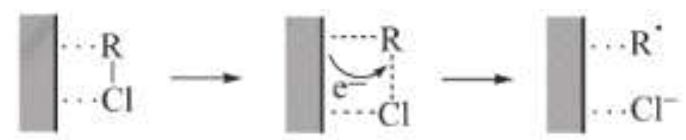

(b)

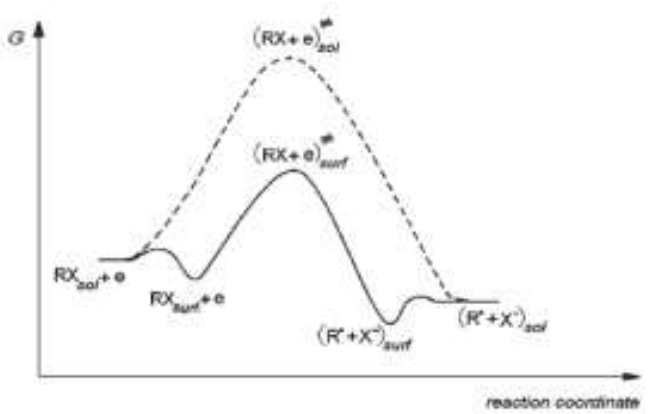

Fig. 16 (a) Schematic diagram of the concerted dissociative DET at Ag; (b) reaction coordinate diagram: outer-sphere DET (dashed curve) and Ag catalyzed DET (solid curve) [143].

The electrocatalytic activity of Ag toward organic halides is significantly affected by (1) the molecular structure of the target component, (2) the presence of a proton source and (3) the morphological feature of Ag. In more details:

(1) It has been proved that the affinity of $\mathrm{Ag}$ for $\mathrm{R}-\mathrm{X}$ decreases following the order $\mathrm{I}>\mathrm{Br}>$ $\mathrm{Cl}$ [132, 145]. Fig. 10 represents the electrocatalytic ability of Ag toward the reductive dehalogenation process estimated upon the difference $E_{p}(M)-E_{p}(G C)$ measured by voltammetry. According to Fig. 17, organic bromides have the highest $\mathrm{E}_{\mathrm{p}}(\mathrm{M})-\mathrm{E}_{\mathrm{p}}(\mathrm{GC})$ values which decrease according to the sequence $\mathrm{I} \approx \mathrm{Br}>\mathrm{Cl}$. This underlines the importance of the nature of the $\mathrm{X}$ group on the catalytic behavior. For example, the adsorption of benzyl chloride and bromide on $\mathrm{Ag}$ is moderate. In contrast, the adsorption of benzyl iodide on the $\mathrm{Ag}$ surface is so strong and fast that the reduction peak of adsorbed benzyl iodide is about 150 $\mathrm{mV}$ more negative than that of dissolved benzyl iodide [132]. Therefore, the low initial catalytic activity found for benzyl iodide could be explained by its high adsorption strength over Ag surface, since it is accepted that excessive adsorption strength has a negative influence on the final activity. On the other hand, the high reaction rate found for benzyl bromide is relative to the adequate combination of moderate adsorption strength with relatively low bond energy. Besides, such effect is furtherly enhanced by the presence of adsorption auxiliary groups (e.g., -OH). The phenolic compounds, compared to the toluene and anisole ones, have a stronger $\mathrm{R}$... X reactivity on $\mathrm{Ag}$, as exhibited by the $\Delta \mathrm{E}_{\mathrm{Ag}-\mathrm{GC}}$ values (1.10 V/SCE for 4-bromophenol vs. $0.83 \mathrm{~V} / \mathrm{SCE}$ for 4-bromoanisole and $0.86 \mathrm{~V} / \mathrm{SCE}$ for 4bromotoluene) [131]. 


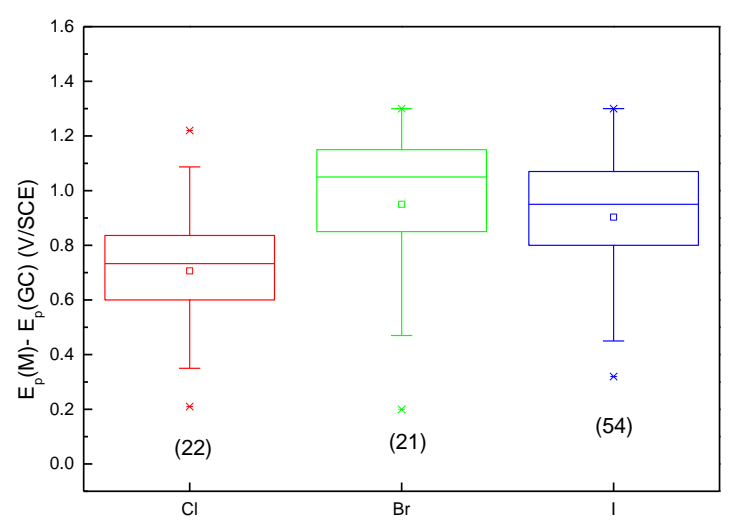

Fig. 17. Experimental electrocatalytic activity scale (referred to the non-catalytic glassy carbon assumption) of $\mathrm{Ag}$ electrode for the reduction of organic chlorides, bromides, and iodides, respectively, in organic medium. The numerals in brackets below the box show the number of data used for each metal. (The horizontal black line in the box represents the median value; the low and upper edges of the box mark the $25^{\text {th }}$ and $75^{\text {th }}$ percentiles, respectively; the little box marks the average value and the extension lines from the box show the highest and lowest values; stars mark outlier) [34, 131-133, 136, 146].

Germinal and vicinal polychloroethanes are another example showing the importance of the molecular structure of organic halides in the electrocatalytic process. Germinal polychloroethanes lose only one chloride in each reduction step, resulting in a totally dechlorinated product, ethane. However, vicinal polychloroethanes undergo the simultaneous removal of two chlorine atoms in an overall $2 \mathrm{e}$ - process leading to the formation of (chloro-) ethylene, which can be further reduced at more negative potentials [34].

(2) The presence of a proton source dramatically affects the hydrodehalogenation mechanism and efficiency. This can be explained by the acceleration of the rate of regeneration of the active sites on the metal surface [147]. For example, in the presence of acetic acid, the production yield of methane $(81 \%)$ after dechlorination of $\mathrm{CCl}_{4}$ at $-2.2 \mathrm{~V} / \mathrm{SCE}$ is much higher than in its absence (11.5\%). Furthermore, the reduction peaks of aliphatic chlorides at $\mathrm{Ag}$ cathode appear less negative in water medium than in aprotic solvent (e.g., dimethylformamide (DMF) or acetonitrile $(\mathrm{ACN})$ ). A possible explanation is that water facilitates the desorption of halogenated compounds from Ag surface, leading to free catalytic sites [148].

(3) The morphology feature of Ag can slightly modulate the electrocatalytic ability of the electrode toward organic halide reduction. According to the cyclic voltammetry analysis of 2,3,4,6-tetra-O-acetyl- $\alpha$-D-glucopyranosyl bromide on Ag monocrystals, Ag with (111) facets exhibits the most positive peak potential $(-1.20 \mathrm{~V} / \mathrm{SCE})$, followed by those with (110) facets ($1.23 \mathrm{~V} / \mathrm{SCE})$ and $(100)$ facets $(-1.31 \mathrm{~V} / \mathrm{SCE})[140]$. The authors also underlined that the catalytic activity of $\mathrm{Ag}$ increases with the surface roughness (on polycrystalline electrodes) or atomic density (on monocrystalline electrodes). Bansal et al. found that nanomaterials show enhanced electrocatalytic activity compared with macro-Ag electrode [127]. Significantly, Ag 
nanoprisms that are rich in hexagonally closed pack (hcp) defects show a greater activity than nanospheres and nanocubes for all reactions studied; for example, the electrocatalytic oxidation of hydrazine and formaldehyde and the reduction of hydrogen peroxide. Similar results were reported by Sui et al. who showed that Ag nanoparticles of $9 \mathrm{~nm}$ size formed in situ with a ZSM-5 zeolite film grown on a stainless steel substrate possessed much higher catalytic activity towards the electroreduction of $\mathrm{PhCH}_{2} \mathrm{Cl}$ compared with an $\mathrm{Ag}$ bulk electrode [149]. The authors suggested that in addition to an increased conductivity and active surface area of the electrode, Ag NPs were stabilized by ZSM-5 zeolite which in turn enhanced the catalytic activity of the NPs.

\section{$4.2 \mathrm{Cu}$}

$\mathrm{Cu}$, in the same group as $\mathrm{Ag}$ in the chemical periodic table, has the advantages of excellent electrical conductivity, only $6 \%$ less than that of $\mathrm{Ag}$, and much lower price, making it a good candidate for applications in environmental remediation. It has been proved that $\mathrm{Cu}$ can exhibit a very good electrocatalytic activity, as shown by the positive shift of the reduction potential of some halogenated compounds compared with glassy carbon $[34,135]$. The results from Isse et al. [134] pointed out that the reduction mechanism of polychloromethanes at $\mathrm{Cu}$ is similar to that of $\mathrm{Ag}$ both in the absence and presence of proton donors. The proton availability of the medium affects both the catalytic effect of $\mathrm{Cu}$ and the distribution of the reduction products. The presence of an added proton donor promotes the hydrodehalogenation pathway, enhancing the concentration of polychloromethanes intermediates and the production yield of methane, which is the primary product of the exhaustive electrolysis. Esclapez et al. [150] have shown by surface-enhanced Raman spectroscopy analyses that trichloroacetic acid can be reduced on $\mathrm{Cu}$ at $-1.3 \mathrm{~V} / \mathrm{sCE}$, due to its high adsorption on the electrode surface via $\mathrm{Cu}-\mathrm{Cl}$ and $\mathrm{Cu}-\mathrm{CO}$ bonds, showing that the carboxylate group participates to the interaction. For this reaction, a two-electron reduction process has been proposed, for example for 1,1,1-trichloroacetate and 1,1-dichloroacetate. The protons participate to the cleavage of the $\mathrm{C}-\mathrm{Cl}$ bond as shown in the equations (15) and (16) [150]. The enhancement of the hydrodehalogenation process in the presence of a suitable proton donor was also proved by Durante et al. [135] and Isse et al. [134].

$\mathrm{Cl}_{3} \mathrm{CCO}_{2}^{-}+\mathrm{H}^{+}+2 \mathrm{e}^{-} \rightarrow \mathrm{HCl}_{2} \mathrm{CCO}_{2}^{-}+\mathrm{Cl}^{-} \ldots$
$\mathrm{HCl}_{2} \mathrm{CCO}_{2}^{-}+\mathrm{H}^{+}+2 \mathrm{e}^{-} \rightarrow \mathrm{H}_{2} \mathrm{ClCCO}_{2}^{-}+\mathrm{Cl}^{-}$

\subsection{Pd}

Pd was found to be effective to reduce organic halides by electrocatalytic hydrogenolysis $(\mathrm{ECH})$ owing to the strong adsorption of hydrogen into its lattice and the further formation of active atomic hydrogen $[\mathrm{H}][75,151,152]$. ECH is the main mechanism that occurs on Pd to break the carbon-halogen bond [32]. ECH is a process in which chemisorbed hydrogen is generated at the cathode surface through reduction of water. More precisely, the $\mathrm{ECH}$ process consists in the following steps [32, 66]: 
(1) generation of chemisorbed hydrogen $[\mathrm{H}]_{\mathrm{ads}-\mathrm{M}}$ on the electrode surface by hydrogen adsorption (equation (17));

(2) adsorption of organic halides (R-X)ads-M on the electrode surface (equation (18));

(3) hydrogenation of (R-X) ads-M by $[\mathrm{H}]_{\text {ads-M }}$ (equation (19));

(4) desorption of the generated dechlorinated organic compound (equation (20)).

$$
\begin{aligned}
& 2 \mathrm{H}_{2} \mathrm{O}+2 \mathrm{e}^{-}+\mathrm{M} \rightarrow 2[\mathrm{H}]_{\text {ads-M }}+2 \mathrm{OH}^{-} \\
& \mathrm{R}-\mathrm{X}+\mathrm{M} \leftrightarrow(\mathrm{R}-\mathrm{X})_{\text {ads }-\mathrm{M}} \\
& (\mathrm{R}-\mathrm{X})_{\mathrm{ads}-\mathrm{M}}+2[\mathrm{H}]_{\text {ads-M }} \rightarrow(\mathrm{R}-\mathrm{H})_{\mathrm{ads}-\mathrm{M}}+\mathrm{HX}
\end{aligned}
$$

Where $\mathrm{M}$ is the metallic Pd surface and $[\mathrm{H}]_{\mathrm{ads}-\mathrm{M}}$ is the chemisorbed hydrogen.

It should be noted that during the ECH, the hydrogen evolution reaction (HER) (equations (21) and (22) competes with the reduction of organic halides [32] if too many protons are accumulated on the Pd surface. Hence, the rate of water reduction (equation (21)) should be lower than the rate of organic halides hydrogenation step (equation (19)). Otherwise, the evolved $\mathrm{H}_{2}$ could form a layer covering the electrode surface and limiting the mass transfer of the organic halides to the active sites. As a result, the hydrodehalogenation of organic halides will be counteracted [96]. Li and Farrell [153] found that high current efficiencies (> 90\%) could be achieved by coating palladized-Fe cathodes by a hydrophobic polymer to inhibit water reduction during trichloroethene reduction.

$[\mathrm{H}]_{\text {ads-M }}+\mathrm{H}_{2} \mathrm{O}+\mathrm{M}+\mathrm{e}^{-} \rightarrow \mathrm{H}_{2}+\mathrm{OH}^{-}$

$[\mathrm{H}]_{\text {ads }-\mathrm{M}}+[\mathrm{H}]_{\mathrm{ads}-\mathrm{M}} \leftrightarrow \mathrm{H}_{2}$

Therefore, considering that the HER is competing with the $\mathrm{ECH}$, control of the $\mathrm{pH}$ of the solution should be taken into account. It was for example reported that the relative kinetics of ECH of 2,4-DCP and HER over Pd NPs can be tuned by controlling the pH. The authors especially presented the utilization of weak acids as an interesting approach to optimize $\mathrm{H}_{\text {ads-M }}$ generation and 2,4-DCP adsorption to enhance the ECH [154]. The electrocatalytic dehalogenation of $\mathrm{CCl}_{4}$ has also been studied in room temperature ionic liquids over reduced graphene oxide (GO) supported $\mathrm{Pd}, \mathrm{Ag}$ and $\mathrm{Ag} / \mathrm{Pd}$ nanodeposits [155]. In the case of Pd-GO electrodes, the mechanism associated with the dehalogenation of $\mathrm{CCl}_{4}$ was described as a modified Sticky dissociative electron transfer (MSDET) mechanism with adsorption energy of chlorinated species contributing to the kinetics of the overall process. However, in the presence of Ag, the mechanism followed a modified stepwise ET model mainly driven by the adsorptive stabilization of the electrogenerated radical anion intermediate onto the electrode surface. In the latter case, it was explained that the stabilization of the radical anion would increase in the driving force for dechlorination reaction of $\mathrm{CCl}_{4}$ [155] 
The morphology feature and size of Pd NPs, the molecular structure of the target component, and the presence of protons source significantly affect the electrocatalytic activity of $\mathrm{Pd}$ toward organic halides:

(1) Nanoparticle shape and size effect

Interestingly, Pd NPs allow a strong and stable adsorption of hydrogen in the Pd lattice as with bulk Pd [156]. Whereas hydrogen-storage capacities and equilibrium hydrogen pressure were proved to decrease with the particle size, the concentration of hydrogen inside the nanoparticle was found to be at least as high as in bulk Pd [157]. The crystalline surface structure has a significant effect on the surface reaction, and controlling the shape of the NPs can help to obtain the desired surface structure to improve their catalytic properties [158]. When NPs are synthesized with a particular shape, they can have a well-defined surface structure, as shown in Fig. 18. For example, the cubic shape of face-centered cubic (fcc) NPs has (100) facets, and tetrahedral, octahedral, and icosahedral fcc NPs have (111) facets. Truncated octahedral have both (100) and (111) facets. The shaped NPs with a distinct surface atomic arrangement would show different catalytic properties. Better catalysts with higher activity and selectivity can potentially be formed by moderating the shapes of NPs. These different atomic arrangements influence the adsorption of reactants onto the surface or the bond cleavage during the surface reaction [158]. For instance, active hydrogen is more stable on (111) facets than on (100) facets since the adsorption energy of hydrogen on $\mathrm{Pd}(111)$ facets is stronger than that on (100) facets [159]. He et al. [96] attributed the high catalytic activity of Pd NPs toward the dechlorination of 2,4-D to their high amount of (111) facets associated with a high number of atoms on edge/corner sites, compared with Pd NPs with mainly (100) facets.

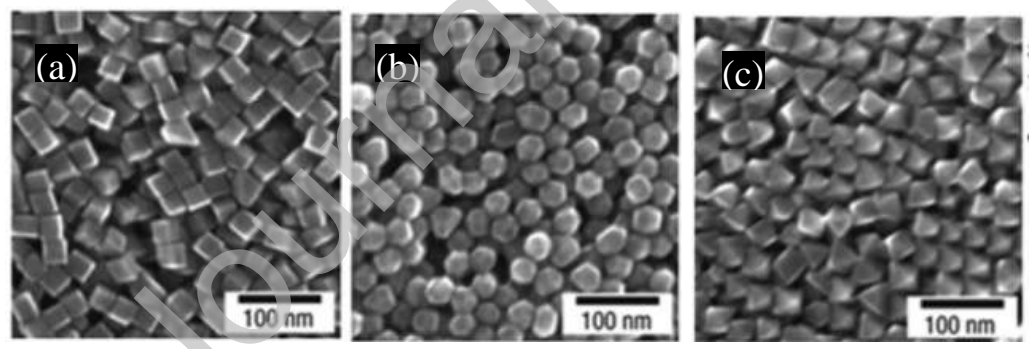

Fig. 18. Pd NPs with cubic (a), cuboctahedral (b), and octahedral (c) shapes [158].

It was also reported that the shape, activity and stabilization of the NPs can be greatly influenced by the utilization of an interlayer [160]. Indeed, Pd NPs electrodeposited on an interlayer film composed of polyaniline-nickel hexacyanoferrate-carbon nanotubes appeared as "spike-like" clusters. In addition, the electrodes prepared with an interlayer exhibited a much higher catalytic activity towards the dechlorination of 4-chlorophenol than those without interlayer [160]. Similar effects were reported with the utilization of various interlayers, such as carbon nanotubes [100, 161], graphene-based materials [162-164], or titanium-based interlayers $[165,166]$

(2) Component's molecular structure effect 
The molecular structure of organic halides has a significant effect on Pd performance. The ease of $\mathrm{C}-\mathrm{X}$ bond hydrogenolytic cleavage is based on the type of halogen involved, the presence of other functional groups and the conditions considered for the reaction. Alkyl halides are removed less readily than benzyl, aryl, or vinyl halides, and for all types of halogen compounds the reactivity order is $\mathrm{RI}>\mathrm{RBr}>\mathrm{RCl} \gg \mathrm{RF}$ [167], which is similar to the dissociation energy of carbon-halogen bonds (Table 2). Li et al. [130] and Korte et al. [168] found that during the dechlorination of phenoxy herbicides in aqueous medium by electrocatalytic reduction over Pd-loaded carbon felt, chlorines positioned in meta or para of the hydroxyl group in dichlorophenol are more susceptible to be attacked by active hydrogen adsorbed on the surface of the electrode than chlorines positioned in ortho. In Han's work [169], ortho-chlorophenol was the most stable in monochlorophenols and harder to be attacked because of the presence of intramolecular hydrogen bonding resulting from the interaction between the hydroxyl group and the ortho-substituted chlorine and to steric hindrance effect.

Table 2 Homolytic bond dissociation energies for $\mathrm{C}-\mathrm{X}, \mathrm{C}-\mathrm{C}, \mathrm{C}=\mathrm{O}$, and $\mathrm{C}=\mathrm{C}$ bonds. [170]

\begin{tabular}{ll}
\hline Bond & $\mathrm{kJ} \mathrm{mol}^{-1}$ \\
\hline $\mathrm{CH}_{3}-\mathrm{F}$ & 451 \\
$\mathrm{CH}_{3}-\mathrm{Cl}$ & 349 \\
$\mathrm{CH}_{3}-\mathrm{Br}$ & 293 \\
$\mathrm{CH}_{3}-\mathrm{I}$ & 234 \\
$\mathrm{CH}_{3}-\mathrm{CH}_{3}$ & 268 \\
$\mathrm{CH}_{3}-\mathrm{H}$ & 439 \\
\hline
\end{tabular}

\subsection{Multi-metal catalysts effect}

Multi-metal catalysts are particularly interesting since they can exhibit synergistic properties due to favorable metal-metal interactions as well as increasing the robustness and durability of the electrodes [99, 100, 163]. The origins of their beneficial catalytic effect can be grouped into two categories [171, 172]:

(1) The improvement of the electronic properties of the cathode influencing the adsorption and/or activation energies (ligand effect). A visibly enhanced catalytic activity toward the reduction of benzyl bromide was achieved on Ag NPs immobilized on a Ni substrate, with $65 \mathrm{mV} / \mathrm{SCE}$ positive shift of the reduction peak compared with Ag NPs deposited on a glassy carbon substrate [173]. It has also been shown for the formation of Ag-Ni alloy that an increased amount of Ni can decrease the size of Ag-Ni NPs, shifting the reduction potential of benzyl chloride positively, and enhancing the catalytic activity of Ag-Ni NPs [174, 175]. The increase of the catalytic activity has been attributed by the authors to the modification of the electronic properties of $\mathrm{Ag}$ by metallic $\mathrm{Ni}$ (and hence the adsorption affinity) by decreasing the adsorption strength for some intermediates. Li et al. [94] found that introducing $\mathrm{Fe}(0)$ in Pd NPs could improve the $\operatorname{Pd}(0)$ dispersion state and take up chloride ions coming from dechlorination of acetic acid, leaving $\operatorname{Pd}(0)$ active. Peng et al. [32] also observed an 
improvement of the hydrodehalonation of tetrabromobisphenol A by Pd NPs when adding $\mathrm{Fe}(0)$, which was attributed to a change in the electronic state of metals, leading to a decrease of the interface impedance and to an enhancement of the electron transfer rate at the electrode. Similarly, Vanrenterghem et al. [171] observed a $34 \mathrm{mV}$ positive shift of the reduction peak potential of benzyl bromide with Ag NPs on Au compared to that measured with Ag NPs on a GC substrate. Authors explained this enhancement in catalytic activity by the suppression of adsorbed poisonous species and a change in the electronic band structure.

(2) The synergistic effect in multi-functional systems whereby each metal plays a different role in the reaction mechanism. To further improve the electrocatalytic ability of palladized cathodes, Ag NPs were added into Pd electrodes. Indeed, the insertion of Ag NPs can actively enhance the hydrodehalogenation ability. He et al. [176] found that the conversion of dichloroacetic acid on a $\mathrm{Pd} / \mathrm{Ag} / \mathrm{Ni}$ foam electrode is at least $15 \%$ higher than on $\mathrm{Pd} / \mathrm{Ni}$ foam without $\mathrm{Ag}$. Ag is known to adsorb chlorinated organic compounds [174] and Pd has a high ability to intercalate hydrogen within its lattice [85]. Therefore, the synergistic effect of $\mathrm{Ag}$ and $\mathrm{Pd}$ increases the amount of $[\mathrm{H}]_{\mathrm{ads}}-\mathrm{M}$ that can react with organic halides. As a result, the current efficiency obtained with $\mathrm{Pd} / \mathrm{Ag} / \mathrm{Ni}$ foam electrode towards the reduction of dichloroacetic acid (62\%) is significantly higher than with $\mathrm{Pd} / \mathrm{Ni}$ foam electrode (13\%) even after five cycles of dechlorination. Roughened Ag-Pd cathodes showed higher current efficiency (77.9\%) and less 2,4-dichlorophenoxyacetic acid (2,4-D) residue (13.5\%), in comparison with Pd-modified glassy carbon (current efficiency $1.6 \%$ and $98.3 \%$ residual 2,4D), for the electrocatalytic reductive dechlorination of 2,4-D in $0.5 \mathrm{M} \mathrm{NaOH}$ [66]. $\mathrm{Cu}$ nanoparticles associated with Ag NPs in a bimetallic system have also attracted much attention. $\mathrm{Ag} / \mathrm{Cu} \mathrm{NPs}$ are more active than bulk $\mathrm{Ag}$ and $\mathrm{Cu}$ toward $\mathrm{R}-\mathrm{X}$ reduction and a positive shift of 0.3-0.5 $\mathrm{V}$ was obtained compared with the non-catalytic electrode, glassy carbon [43]. Furthermore, the mixed agglomerates of $\mathrm{Ag}$ and $\mathrm{Cu}$ NPs have shown a more reproducible behavior than the sole $\mathrm{Cu}$ NPs and this is possibly due to inhibition of the oxidation $\mathrm{Cu}$ NPs when exposed to air in presence of Ag. Synergistic effects in multi-metal systems can also offer economic and environmental advantages. For instance, Lou et al. have shown that the addition of $\mathrm{MnO}_{2}$ could greatly enhance the catalytic activity of a $\mathrm{Pd} / \mathrm{Ni}$ foam electrode while decreasing the Pd loading by $75 \%$ [177]. The authors concluded that by promoting the Volmer reaction (water dissociation), $\mathrm{MnO}_{2}$ provides more active atomic hydrogen $[\mathrm{H}]$ that can be further stored by $\mathrm{Pd}$, hence achieving a faster complete dechlorination of 2,4-dichlorobenzoic acid (2,4-DCBA) [177]. Lou et al. also showed that optimal loadings must be found for both $\mathrm{MnO}_{2}$ and $\mathrm{Pd}$ in order to favour the $\mathrm{ECH}$, as excessive Pd loading favours the competing HER [178].

However, it should be noted that all multi-metals modified electrodes do not always exhibit a better catalytic ability. For example, the reduction of benzyl bromide is not improved on $\mathrm{Ag}$ NPs modified with $\mathrm{Ti}$ (reduction peak at $-1.38 \mathrm{~V} / \mathrm{SCE}$ ) compared with Ag NPs modified glassy carbon (reduction peak at $-0.96 \mathrm{~V} / \mathrm{SCE}$ ) [173]. According to the authors, the decrease of the catalytic activity is not due to an alternative reaction mechanism but rather by the interplay between NPs and the Ti support. 


\section{Applications}

The electrocatalyst, the applied cathode potential, the nature of halide and the electrolyte are important parameters that determine the selectivity and the reduction efficiency of organic halide removal [179]. In general, vinyl halides are more easily reduced than halo-alkanes, with reduction peaks at more positive potentials. Similarly, the reduction of monohalides more favorable than that of vicinal dihalides, which in turn can be more easily reduced than gem-dihalides. Higher reduction efficiency is obtained in alkaline electrolyte than in neutral or acid medium, due to the stronger competition with hydrogen evolution reaction (HER). Although many studies have been carried out in organic media to evaluate the electrodechlorination performances of metallic NPs modified-electrodes, these electrodes are ultimately designed for environmental applications in aqueous media potentially containing concentrated pollutants. Hence, we list in Table 3 recent examples of lab-scale applications using metallic NPs modified-cathodes for dehalogenation of organic halides in aqueous solution. Four groups of organic halides, including chlorinated phenoxyacetic acid, phenol derivatives, acetic acid, and biphenyl herbicides, are the most commonly investigated pollutants in aqueous medium. Three of them were vinyl halides. It should be noted that although these experiments were carried out in aqueous media, methanol was sometimes added into the electrolyte to increase the solubility of these organic halides, as well as to enhance mass transfer. Researchers have investigated the effect of methanol on the dechlorination process, but none has mentioned that methanol participates in the dechlorination reaction [180].

Pd is often used for dehalogenation in aqueous medium due to its strong ability to intercalate hydrogen in Pd lattice for ECH. The current efficiencies obtained on Ag electrodes are generally higher than those of $\mathrm{Pd}$ since the reaction is usually performed at less negative potential than HER. High current efficiencies could be obtained (66\% and $100 \%$ for entry 1 and 23 of Table 3, respectively) but they are usually below 30\%. As explained before, bimetallic particles of $\mathrm{Ag}$ and $\mathrm{Pd}$ favor high current efficiencies thanks to more selective adsorption cleavage on $\mathrm{Ag}$ (entry 1). Interestingly, the use of polymeric pyrrole-cetyl trimethyl ammonium bromide (PPY-CTAB) before Pd deposition was shown to be effective to prepare electrode with large surface area and lower Pd loading [92].

Implementing electrocatalytic reduction of organic halides for the treatment of real wastewater is another challenge given the complexity of the matrix of the effluent. Indeed, the presence of various organic and inorganic compounds might severely hinder the reduction of the target compound and in turn decrease the removal efficiency [145, 181]. In addition, the low conductivity of real wastewaters (compared to synthetic effluents) is often a major bottleneck for the development of electrochemical technologies for environmental remediation. Reduced sulfur compounds (RSCs), coming partly from microbial anaerobic reaction or contained in the natural organic matter, have shown a poisoning effect on the $\mathrm{Pd}$ catalytic ability for electrocatalytic dechlorination in aqueous medium, by the adsorption of sulfur and the formation of palladium sulfide on the catalyst surface [57, 85, 182]. In that case, 
the hydrogen adsorption inside Pd lattice is hindered, and the mobility of the hydrogen atoms located on the catalyst surface is reduced. To solve this problem, some oxidizing agents, like $\mathrm{H}_{2} \mathrm{O}_{2}$ or hypochlorite, have been tested to regenerate the catalyst activity [183, 184]. Xu et al. [26] found that the presence of $\mathrm{Cl}^{-}$hinders the ECH dechlorination, blocking the reaction sites by adsorbed $\mathrm{HCl}$ produced by catalytic hydrogenation step between adsorbed 2,4-D and chemisorbed hydrogen. Adsorbed $\mathrm{HCl}$ could be released by the neutralization effect of $\mathrm{OH}^{-}$. It has also been shown that ethanol deactivates the $\mathrm{Pd} / \mathrm{Ag}$ cathode activity if an aqueous alkaline solution is used for the ECH dechlorination of 2,4-D. Indeed, ethanol can dissociatively chemisorb on Ag to form Ag ethoxide at room temperature [185]. Meanwhile, Du et al. [24] showed that the removal rate of 2,4-DCP on $\mathrm{Pd} / \mathrm{TiO}_{2} \mathrm{NTs} / \mathrm{Ti}$ electrode decreased from $91 \%$ to $35 \%$ after 5 cycles reuse. This result was ascribed to the poisoning effect of the phenol produced and the formation of palladium oxide. Anions including sulfate, nitrate, sulfide, and carbonate are frequently present in groundwater or surface water and can affect the dechlorination processes. For example, $\mathrm{CO}_{3}{ }^{2-}$ and $\mathrm{NO}_{3}{ }^{-}$are known to react with $\mathrm{H}_{2}$ as described in equations (23) and (24) [186, 187]:

$\mathrm{HCO}_{3}^{-}+\mathrm{H}_{2} \rightarrow \mathrm{HCO}_{2}^{-}+\mathrm{H}_{2} \mathrm{O} \cdots \cdots \cdots$
$2 \mathrm{NO}_{3}^{-}+5 \mathrm{H}_{2} \rightarrow \mathrm{N}_{2}+2 \mathrm{OH}^{-}+4 \mathrm{H}_{2} \mathrm{O}$ 
Table 3. Application of nanoparticle metal catalyst modified cathodes on dehalogenation of organic halide in aqueous solutions.

\begin{tabular}{|c|c|c|c|c|c|c|c|c|c|c|c|c|}
\hline Entry & Probe & $\begin{array}{l}\text { Initial } \\
\text { concentration } \\
\left(\mathrm{mmol} \mathrm{L}^{-1}\right)\end{array}$ & Electrolyte & $\begin{array}{l}\text { Nature of the } \\
\text { cathode }\end{array}$ & $\begin{array}{l}\text { Nanoparticle } \\
\text { size and loading }\end{array}$ & $\begin{array}{l}\text { Preparation } \\
\text { method }\end{array}$ & $\begin{array}{l}\text { Applied } \\
\text { current } \\
\left(\mathrm{mA} / \mathrm{cm}^{2}\right) \\
\text { or } \\
\text { potential } \\
\text { (V) }\end{array}$ & $\begin{array}{l}\text { Main } \\
\text { Products } \\
\text { (Yield) }\end{array}$ & $\begin{array}{l}\mathrm{CE} \\
\%\end{array}$ & $\begin{array}{l}\text { Conversion } \\
\%\end{array}$ & $\begin{array}{l}\text { Time } \\
(\min )\end{array}$ & Ref. \\
\hline 1 & $2,4-\mathrm{D}$ & 25 & $0.5 \mathrm{~mol} \mathrm{~L}^{-1} \mathrm{NaOH}$ & $\begin{array}{l}\text { Palladized } \\
\text { roughened Ag }\end{array}$ & $\begin{array}{l}0.9 \\
\mathrm{mg} \mathrm{cm}^{-2}\end{array}$ & GRR & $-2.1--4.2$ & $\begin{array}{l}\text { PA } \\
(85 \%)\end{array}$ & 66 & 92.3 & 360 & [26] \\
\hline 2 & $\begin{array}{l}2,4-\mathrm{D} \\
2,4,5-\mathrm{T}\end{array}$ & 50 & $\begin{array}{l}\mathrm{MeOH} 40 \%(\mathrm{v} / \mathrm{v}) \\
0.50 \mathrm{~mol} \mathrm{~L}^{-1} \mathrm{TBAB} \\
0.50 \mathrm{~mol} \mathrm{~L}^{-1} \text { TFAA }\end{array}$ & $\begin{array}{l}\text { Palladized } \\
\text { carbon felt }\end{array}$ & $\begin{array}{l}5 \mathrm{wt} . \% \text { or } \\
0.06 \text { to } 2.02 \mathrm{mg} \\
\mathrm{cm}^{-2}\end{array}$ & $\mathrm{CR}$ & -111 & $\begin{array}{l}\text { PA } \\
(80-93 \%)\end{array}$ & $\begin{array}{l}\text { Up to } \\
20\end{array}$ & $94-100$ & 240 & {$[188]$} \\
\hline 3 & 2,4-D & 0.23 & $0.01 \mathrm{~mol} \mathrm{~L}^{-1} \mathrm{Na}_{2} \mathrm{SO}_{4}$ & $\begin{array}{l}\mathrm{Pd} / \mathrm{TiN} @ \mathrm{Ni} \\
\text { foam }\end{array}$ & $0.44 \mathrm{mg} \mathrm{cm}^{-2}$ & GRR & -1.667 & PA $(100 \%)$ & $4-10$ & 100 & 120 & {$[75,85]$} \\
\hline 4 & 2,4-D & $0.23-0.90$ & $0.034 \mathrm{~mol} \mathrm{~L}^{-1} \mathrm{NaCl}$ & Pd@Ni foam & $1.78 \mathrm{mg} \mathrm{cm}^{-2}$ & GRR & -1.667 & $\begin{array}{l}\mathrm{PA} \\
(83 \%)\end{array}$ & $4-10$ & 87 & 240 & [31] \\
\hline 5 & 2,4-D & 0.226 & $0.0342 \mathrm{~mol} \mathrm{~L}^{-1} \mathrm{NaCl}$ & Pd@Ni foam & $\begin{array}{l}20 \mathrm{~nm}, \\
1.40 \mathrm{mg} \mathrm{cm}^{-2}\end{array}$ & ELE & -1.5 & PA $(>90 \%)$ & 14 & 98 & 180 & [96] \\
\hline 6 & $\mathrm{PCP}$ & 0.75 & $\begin{array}{l}\mathrm{MeOH} 40 \%+0.25 \\
\text { mol L-1 TMACl }\end{array}$ & $\begin{array}{l}\text { Pd-loaded } \\
\text { activated carbon } \\
\text { fiber }\end{array}$ & $\begin{array}{l}2.13 \mathrm{~nm} \\
4.2 \mathrm{w} . \%\end{array}$ & $\begin{array}{l}\text { Impregnate } \\
d+\text { ELE }\end{array}$ & -25 & $\begin{array}{l}\text { Phenol } \\
(86.1 \%)\end{array}$ & 17.4 & 98.4 & 200 & [189] \\
\hline 7 & $\mathrm{PCP}$ & 0.0376 & $\begin{array}{l}\text { Initial } \mathrm{pH} 2.1 \\
0.05 \mathrm{~mol} \mathrm{~L}^{-1} \mathrm{Na}\end{array}$ & $\begin{array}{l}\mathrm{Pd}- \\
\mathrm{Ni}(\mathrm{CTAB}) / \mathrm{Ti} \\
\text { mesh }\end{array}$ & $\begin{array}{l}4.22 \mathrm{~nm} \text { by } \\
\text { Scherrer equation } \\
1.22-2.21 \\
\mathrm{mg} \mathrm{cm}^{-2}\end{array}$ & ELE & -0.375 & $\begin{array}{l}\text { Phenol } \\
(27.5 \%)\end{array}$ & -- & 100 & 90 & {$[101]$} \\
\hline 8 & 2,4-DCP & 0.5 & $0.05 \mathrm{~mol} \mathrm{~L}^{-1} \mathrm{Na}_{2} \mathrm{SO}_{4}$ & $\mathrm{Pd} / \mathrm{PPY}_{(\mathrm{PTS})} / \mathrm{Ni}$ & $\begin{array}{l}10 \mathrm{~nm} \\
0.226 \mathrm{~nm} \text { by } \\
\text { Scherrer equation }\end{array}$ & ELE & -1.67 & $\begin{array}{l}\text { Phenol } \\
(82 \%)\end{array}$ & -- & 90.9 & 100 & {$[60]$} \\
\hline
\end{tabular}




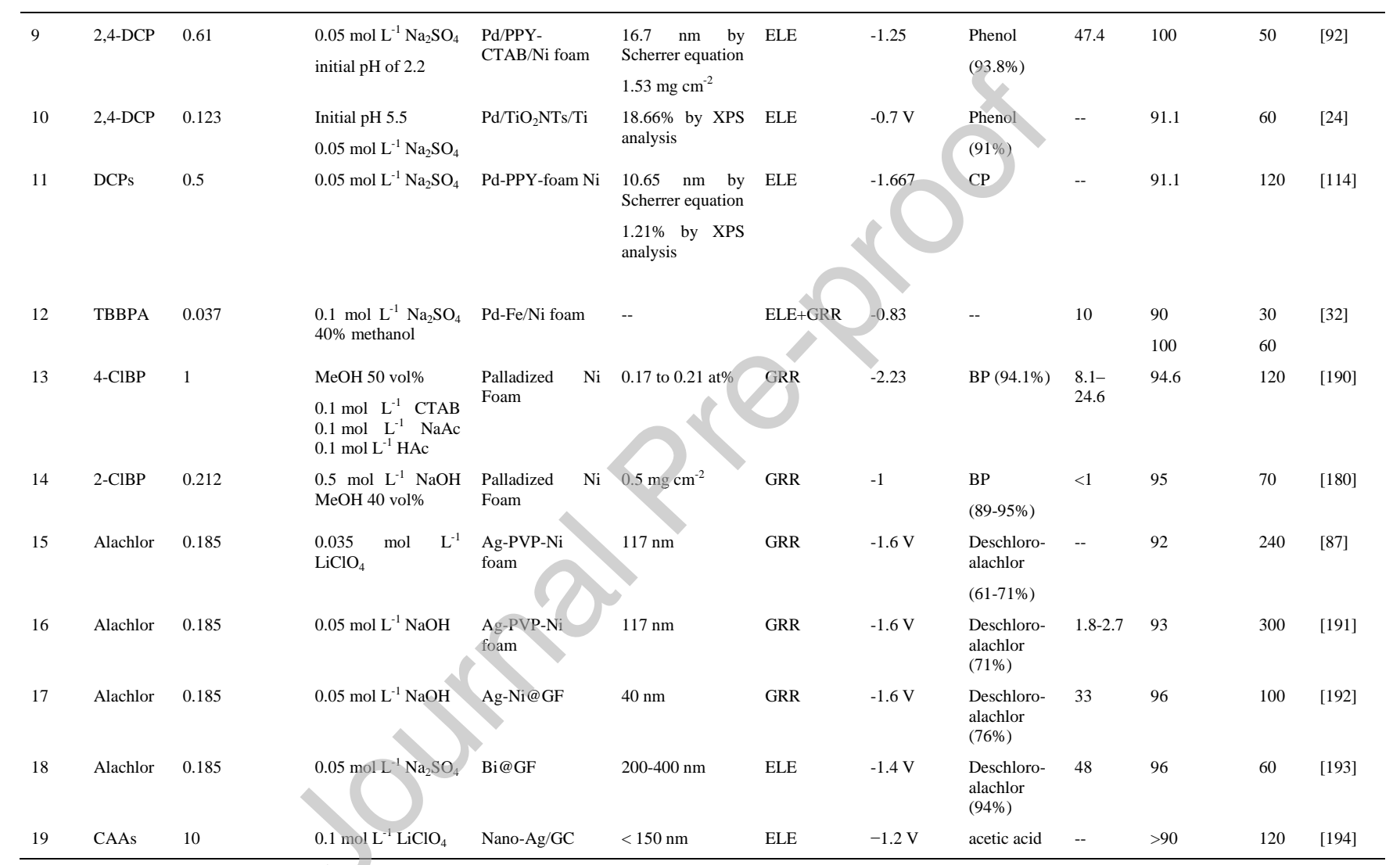




\begin{tabular}{|c|c|c|c|c|c|c|c|c|c|c|c|c|}
\hline 20 & CAAs & $3.1 \times 10^{-3}$ & $0.01 \mathrm{~mol} \mathrm{~L}^{-1} \mathrm{Na}_{2} \mathrm{SO}_{4}$ & $\begin{array}{l}\mathrm{Pd} / \mathrm{Fe} / \text { Carbon } \\
\text { paper }\end{array}$ & $\begin{array}{l}20 \mathrm{~nm} \\
0.32-0.46 \\
\mathrm{wt} \%\end{array}$ & ELE & $-1.5 \mathrm{~V}$ & Acetic acid & -- & 95 & 20 & [94] \\
\hline 21 & CAAs & $0.73 \times 10^{-3}$ & $\begin{array}{l}1.4 \mathrm{mmol} \quad \mathrm{L}^{-1} \\
\mathrm{Na}_{2} \mathrm{SO}_{4}\end{array}$ & $\mathrm{Pd} /$ Carbon paper & $1.41-2.52 \mathrm{wt} \%$ & ELE & 0.3 & Acetic acid & -- & 75 & 20 & {$[48]$} \\
\hline 22 & TCE & 0.16 & $\begin{array}{l}0.01 \mathrm{~mol} \mathrm{~L}^{-1} \\
\mathrm{Na}_{2} \mathrm{SO}_{4}\end{array}$ & $\begin{array}{l}\mathrm{Pd} \quad \text { loaded } \\
\mathrm{Ti} / \mathrm{TiO}_{2} \\
\text { nanotube }\end{array}$ & $\begin{array}{l}46 \mathrm{~nm} \\
6.4 \mathrm{mg} \mathrm{cm}^{-2}\end{array}$ & ELE & -5 & $\begin{array}{l}\text { Ethane } \\
80 \% \text {, } \\
\text { C3-C6 20\% }\end{array}$ & 4 & 91 & 120 & [57] \\
\hline 23 & $\mathrm{CHCl}_{3}$ & 23 & $0.1 \mathrm{~mol} \mathrm{~L}^{-1} \mathrm{Na}_{2} \mathrm{SO}_{4}$ & $\begin{array}{l}\text { Nano-Ag/carbon } \\
\text { powder }\end{array}$ & $\begin{array}{l}10 \mathrm{wt} \% \\
15-20 \mathrm{~nm}\end{array}$ & $\mathrm{CR}$ & -2 & $\mathrm{CH}_{4}(40 \%)$ & 100 & $50-60$ & 240 & [195] \\
\hline 24 & 2-CP & 0.78 & $\begin{array}{l}0.05 \mathrm{~mol} \mathrm{~L}^{-1} \text { Acetate } \\
\text { buffer }\end{array}$ & $\begin{array}{l}\text { Activated Ti- } \\
0.15 \mathrm{Pd} \text { alloy }\end{array}$ & $46 \mathrm{~nm}$ & & 2.5 & Phenol & -- & 70 & 180 & [196] \\
\hline 25 & $\begin{array}{l}2,4- \\
\text { DCBA }\end{array}$ & 0.156 & $10 \mathrm{mmol} \mathrm{L}^{-1} \mathrm{Na}_{2} \mathrm{SO}_{4}$ & $\mathrm{Pd} / \mathrm{CB}$ & $5 \mathrm{~nm}$ & & 10 & BA & -- & 93.6 & 180 & [161] \\
\hline 26 & $p$-CNB & 0.157 & $50 \mathrm{mmol} \mathrm{L}^{-1} \mathrm{Na}_{2} \mathrm{SO}_{4}$ & $\mathrm{Pd} / \mathrm{Ni}$ foam & & GRR & 10 & Aniline & 10 & 88.2 & 30 & [197] \\
\hline 27 & $\begin{array}{l}2,4- \\
\text { DCBA }\end{array}$ & 0.2 & $10 \mathrm{mmol} \mathrm{L}^{-1} \mathrm{Na}_{2} \mathrm{SO}_{4}$ & TiC-Pd/Ni foam & & GRR & $0.85 \mathrm{~V}$ & BA & -- & 100 & 90 & [165] \\
\hline 28 & $\begin{array}{l}2,4- \\
\text { DCBA }\end{array}$ & 0.2 & $10 \mathrm{mmol} \mathrm{L}^{-1} \mathrm{Na}_{2} \mathrm{SO}_{4}$ & $\mathrm{Pd} / \mathrm{TiC} / \mathrm{Ti}$ & $5 \mathrm{~nm}$ & $\mathrm{CR}$ & $-0.8 \mathrm{~V}$ & $\mathrm{BA}$ & -- & 100 & 480 & [166] \\
\hline 29 & Triclosan & 0.05 & $2 \mathrm{mmol} \mathrm{L}^{-1} \mathrm{Na}_{2} \mathrm{SO}_{4}$ & $\begin{array}{l}\mathrm{Pd} / \mathrm{N}-\mathrm{GR} / \mathrm{Cu} \\
\text { foam }\end{array}$ & $30 \mathrm{~nm}$ & ELE & $\begin{array}{l}-1.2 \mathrm{~V} \text { vs } \\
\text { SCE }\end{array}$ & See ref. & -- & 93.8 & 10 & [164] \\
\hline 30 & $\begin{array}{l}2,3,5- \\
\text { TCP }\end{array}$ & 0.5 & $\begin{array}{l}0.05 \mathrm{mmol} \mathrm{L}^{-1} \\
\mathrm{Na}_{2} \mathrm{SO}_{4}\end{array}$ & $\begin{array}{l}\mathrm{Pd} / \mathrm{rGO}- \\
\text { Nafion/Ti mesh }\end{array}$ & $14 \mathrm{~nm}$ & ELE & 5 & $\begin{array}{l}\text { Phenol } \\
(85 \%)\end{array}$ & 18.5 & 76.5 & 90 & [162] \\
\hline 31 & 3-CP & 0.5 & $\begin{array}{l}0.05 \mathrm{mmol} \mathrm{L}^{-1} \\
\mathrm{Na}_{2} \mathrm{SO}_{4}\end{array}$ & $\mathrm{Pd} / \mathrm{Ni}$ foam & $12 \mathrm{~nm}$ & ELE & 5 & Phenol & -- & 97.0 & 120 & [198] \\
\hline 32 & PCP & 0.19 & $\begin{array}{l}100 \mathrm{mmol} \mathrm{L}^{-1} \\
\mathrm{Na}_{2} \mathrm{SO}_{4}\end{array}$ & $\begin{array}{l}\mathrm{Pd} / \mathrm{CuFe}_{2} \mathrm{O}_{4} / \mathrm{M}- \\
\mathrm{PSBC}\end{array}$ & $5 \mathrm{~nm}$ & $\mathrm{CR}$ & $0.8 \mathrm{~V}$ & $\begin{array}{l}\text { Phenol } \\
(93.1 \%)\end{array}$ & 28.1 & 99.0 & 250 & [199] \\
\hline
\end{tabular}

2,4-dichlorophenoxyacetic acid (2,4-D), galvanic replacement reaction (GRR), phenoxyacetic acid (PA), trichlorophenoxyacetic acid (2,4,5-T), tetra- $n$-butylammonium bromide (TBAB), trifluoroacetic acid (TFAA), chemical reduction (CR), tetramethylammonium chloride (TMACl), pentachlorophenol (PCP), 2-chlorophenol (2-CP), 2,4-dichlorophenol (2,4-DCP), 2,3,5-trichlorophenol (2,3,5-TCP), 2,4-dichlorobenzoic acid (2,4-DCBA), pentachlorophenol (PCP), benzoic acid (BA), para-chloronitrobenzene ( $p$-CNB), tetrabromobispenol A (TBBPA), chloroacetic acids (CAAs), 2-chlorobiphenyl (2-ClBP), trichloroethylene (TCE), trichloroacetic acid (TCAA), chlorophenoxyacetic acid (CPA), 
electrodeposition (ELE), magnetic peanut shell-derived biochar (M-PSBC), cetyltrimethylammonium bromide (CTAB), polypyrrole (PPY), p-toluenesulfonic acid (PTS), titanium nitride (TiN), biphenyl (BP), titania nanotubes $\left(\mathrm{TiO}_{2} \mathrm{NTs}\right)$, hydrofluoric acid $(\mathrm{HF})$ 


\section{Conclusions and Perspectives}

Electroreductive dehalogenation treatment on metallic NPs modified 3D electrode is considered as an effective and environmentally friendly process for the degradation of halogenated persistant organic compounds. Methods used to deposit nanoparticles can be applied to large porous electrodes, allowing the electrochemical process to be used for large-scale treatment. Furthermore, such modified 3D porous electrodes can be easily applied in flow electrochemical systems which are well-adapted to the treatment of high volumes of solution. In addition, considering the abundance of halogenated compounds in refractory pollutants, electroreductive dehalogenation could be applied for the specific treatment of a wide range of concentrated effluents (e.g. agricultural and pharmaceutical effluents) prior to their discharge in conventional wastewater treatment plants to achieve a complete mineralization. It also offers the possibility to recover halides in their anionic forms, allowing their possible reintegration in the production process. In addition to the issue linked to the often low conductivity of real effluents, one of the most challenging points that would allow electroreduction processes to be applied industrially is the improvement of current efficiencies since most compounds are reduced at very negative potentials, thus facing the competition with hydrogen evolution. $\mathrm{Ag}, \mathrm{Pd}$, and $\mathrm{Cu}$ are the most commonly used metals for the synthesis of NPs. As described in this review, the mechanisms of these metals can be influenced by the molecular structure of pollutants, the presence of a proton source, and the morphological feature of NPs. The strong affinity of $\mathrm{RCl}$ with $\mathrm{Ag}$ decreases the activation energy of the concerted DET process so that Ag has a good catalytic ability to organohalogen reduction. The catalytic ability of $\mathrm{Pd}$ can be ascribed to the strong adsorption of hydrogen into its lattice and to the further formation of active atomic hydrogen $[\mathrm{H}]$. Cu has the synthetic ability of adsorption and $\mathrm{ECH}$, but not as strong as $\mathrm{Ag}$ and $\mathrm{Pd}$. A promising approach is to benefit from synergistic effects between metals thanks to multi-metal nanoparticles formation to improve the performances of the dehalogenation process. Such an approach would lead to a multi-catalysts electrodes able to degrade specific positions of the pollutants, thus improving their biodegradability. Another interesting approach, is linked to the the size and shape of NPs that play an important role in the catalytic ability and selectivity of electroreductions. Thus, a homogeneous deposition of NPs on a porous support with a well-controlled morphology should strongly influence the catalytic performance of the electrode. The immobilization of synthetic nanoparticles on electrodes is a good mean to achieve a high control of NPs size and morphology [200]. Interestingly, the ligand used to stabilize NPs during their synthesis can also play an important role in electrocatalysis. It would be also another essential parameter to consider to improve the catalytic properties.

\section{Declaration of interests}


The authors declare that they have no known competing financial interests or personal relationships that could have appeared to influence the work reported in this paper.

\section{Acknowledgement}

Y. Y. Lou thanks the China Scholarship Council (CSC) for a Ph.D. grant.

\section{References}

[1] Persistent organic pollutants: towards a POPs-free future. (European Commission), (2017).

[2] A.K. Halse, M. Schlabach, J.K. Schuster, K.C. Jones, E. Steinnes, K. Breivik, Endosulfan, pentachlorobenzene and short-chain chlorinated paraffins in background soils from Western Europe, Environ. Pollut., 196 (2015) 21-28.

[3] R.R. Solis, F.J. Rivas, O. Gimeno, J.L. Perez - Bote, Synergism between peroxymonosulfate and $\mathrm{LaCoO}_{3}-\mathrm{TiO}_{2}$ photocatalysis for oxidation of herbicides. Operational variables and catalyst characterization assessment, J. Chem. Technol. Biotechnol., 92 (2017) 2159-2170.

[4] H. Chen, Z. Zhang, Z. Yang, Q. Yang, B. Li, Z. Bai, Heterogeneous Fenton-like catalytic degradation of 2, 4-dichlorophenoxyacetic acid in water with FeS, Chem. Eng. J., 273 (2015) 481-489.

[5] F.L. Souza, C. Saéz, M.R.V. Lanza, P. Cañizares, M.A. Rodrigo, Removal of herbicide 2,4-D using conductive-diamond sono-electrochemical oxidation, Sep. Purif. Technol., 149 (2015) 24-30.

[6] O. Scialdone, A. Galia, L. Gurreri, S. Randazzo, Electrochemical abatement of chloroethanes in water: reduction, oxidation and combined processes, Electrochim. Acta, 55 (2010) 701-708.

[7] Z. Chen, Y. Liu, W. Wei, B.-J. Ni, Recent advances in electrocatalysts for halogenated organic pollutant degradation, Environmental Science: Nano, 6 (2019) 2332-2366.

[8] W.M. Latimer, Oxidation potentials, Prentice-Hall, New York, 1952.

[9] Y.-Y. Lou, F. Geneste, I. Soutrel, A. Amrane, F. Fourcade, Alachlor dechlorination prior to an electro-Fenton process: Influence on the biodegradability of the treated solution, Sep. Purif. Technol., 232 (2020) 115936.

[10] A. Aboudalle, H. Djelal, F. Fourcade, L. Domergue, A.A. Assadi, T. Lendormi, S. Taha, A. Amrane, Metronidazole removal by means of a combined system coupling an electroFenton process and a conventional biological treatment: By-products monitoring and performance enhancement, J. Hazard. Mater., 359 (2018) 85-95.

[11] D. Pęziak-Kowalska, F. Fourcade, M. Niemczak, A. Amrane, Ł. Chrzanowski, G. Lota, Removal of herbicidal ionic liquids by electrochemical advanced oxidation processes combined with biological treatment, Environ. Technol., 38 (2017) 1093-1099. 
[12] D. Mansour, F. Fourcade, I. Soutrel, D. Hauchard, N. Bellakhal, A. Amrane, Mineralization of synthetic and industrial pharmaceutical effluent containing trimethoprim by combining electro-Fenton and activated sludge treatment, J. Taiwan Inst. Chem. Eng. , 53 (2015) 58-67.

[13] D. Mansour, F. Fourcade, S. Huguet, I. Soutrel, N. Bellakhal, M. Dachraoui, D. Hauchard, A. Amrane, Improvement of the activated sludge treatment by its combination with electro Fenton for the mineralization of sulfamethazine, Int. Biodeterior. Biodegrad., 88 (2014) 29-36.

[14] A. Ledjeri, I. Yahiaoui, H. Kadji, F. Aissani-Benissad, A. Amrane, F. Fourcade, Combination of the Electro/ $\mathrm{Fe}^{3+} /$ peroxydisulfate (PDS) process with activated sludge culture for the degradation of sulfamethazine, Environ. Toxicol. Pharmacol., 53 (2017) 34-39.

[15] T. Aissani, I. Yahiaoui, F. Boudrahem, S. Ait Chikh, F. Aissani-Benissad, A. Amrane, The combination of photocatalysis process $\left(\mathrm{UV} / \mathrm{TiO}_{2}(\mathrm{P} 25)\right.$ and $\left.\mathrm{UV} / \mathrm{ZnO}\right)$ with activated sludge culture for the degradation of sulfamethazine, Sep. Sci. Technol., 53 (2018) 1423-1433.

[16] I. Saidi, F. Fourcade, D. Floner, I. Soutrel, N. Bellakhal, A. Amrane, F. Geneste, Sulfamethazine removal by means of a combined process coupling an oxidation pretreatment and activated sludge culture-preliminary results, Environ. Technol., 38 (2017) 2684-2690.

[17] J.-M. Fontmorin, J. Siguié, F. Fourcade, F. Geneste, D. Floner, I. Soutrel, A. Amrane, Combined electrochemical treatment/biological process for the removal of a commercial herbicide solution, U46D ${ }^{\circledR}$, Sep. Purif. Technol., 132 (2014) 704-711.

[18] M. Assassi, F. Fourcade, F. Geneste, D. Floner, R. Maachi, A. Amrane, Combined electrochemical and biological treatment for pesticide degradation-application to phosmet, Int. J. Environ. Res., 5 (2011) 41-46.

[19] D. Belkheiri, F. Fourcade, F. Geneste, D. Floner, H. Ait-Amar, A. Amrane, Combined process for removal of tetracycline antibiotic - Coupling pre-treatment with a nickel-modified graphite felt electrode and a biological treatment, Int. Biodeterior. Biodegrad., 103 (2015) 147-153.

[20] J.-M. Fontmorin, F. Fourcade, F. Geneste, D. Floner, S. Huguet, A. Amrane, Combined process for 2,4-Dichlorophenoxyacetic acid treatment-Coupling of an electrochemical system with a biological treatment, Biochem. Eng. J., 70 (2013) 17-22.

[21] M. Zaghdoudi, F. Fourcade, I. Soutrel, D. Floner, A. Amrane, H. Maghraoui-Meherzi, F. Geneste, Direct and indirect electrochemical reduction prior to a biological treatment for dimetridazole removal, J. Hazard. Mater., 335 (2017) 10-17.

[22] F. Geneste, Catalytic electrochemical pre-treatment for the degradation of persistent organic pollutants, Curr. Opin. Electrochem., 11 (2018) 19-24.

[23] G. Chen, Z. Wang, D. Xia, Electrochemically codeposited palladium/molybdenum oxide electrode for electrocatalytic reductive dechlorination of 4-chlorophenol, Electrochem. Commun., 6 (2004) 268-272.

[24] J. Du, J. Bao, W. Hu, Efficient dechlorination of 2, 4-dichlorophenol in an aqueous media with a mild $\mathrm{pH}$ using a $\mathrm{Pd} / \mathrm{TiO}_{2} \mathrm{NTs} / \mathrm{Ti}$ cathode, Frontiers of Environmental Science and Engineering, 9 (2015) 919-928.

[25] A. Brzózka, A. Jeleń, A.M. Brudzisz, M.M. Marzec, G.D. Sulka, Electrocatalytic reduction of chloroform at nanostructured silver electrodes, Electrochim. Acta, 225 (2017) 574-583. 
[26] Y.H. Xu, Q.Q. Cai, H.X. Ma, Y. He, H. Zhang, C.A. Ma, Optimisation of electrocatalytic dechlorination of 2, 4-dichlorophenoxyacetic acid on a roughened silver-palladium cathode, Electrochim. Acta, 96 (2013) 90-96.

[27] P. Poizot, L. Laffont-Dantras, J. Simonet, Palladized silver as new cathode material: Evidence of a one-electron scission for primary alkyl iodides, J. Electroanal. Chem., 622 (2008) 204-210.

[28] L. Yang, Z. Chen, D. Cui, X. Luo, B. Liang, L. Yang, T. Liu, A. Wang, S. Luo, Ultrafine palladium nanoparticles supported on 3D self-supported $\mathrm{Ni}$ foam for cathodic dechlorination of florfenicol, Chem. Eng. J. (Amsterdam, Neth.), 359 (2019) 894-901.

[29] F. Pagnanelli, P. Altimari, M. Bellagamba, G. Granata, E. Moscardini, P.G. Schiavi, L. Toro, Pulsed electrodeposition of cobalt nanoparticles on copper: influence of the operating parameters on size distribution and morphology, Electrochim. Acta, 155 (2015) 228-235.

[30] J. Simonet, P. Poizot, L. Laffont, A copper-palladium alloy usable as cathode material mode of formation and first examples of catalytic cleavages of carbon-halide bonds, J. Electroanal. Chem., 591 (2006) 19-26.

[31] K. Zhu, S.A. Baig, J. Xu, T. Sheng, X. Xu, Electrochemical reductive dechlorination of 2, 4-dichlorophenoxyacetic acid using a palladium/nickel foam electrode, Electrochim. Acta, 69 (2012) 389-396.

[32] Z. Peng, Z. Yu, L. Wang, Y. Hou, Y. Shi, L. Wu, Z. Li, Facile synthesis of Pd-Fe nanoparticles modified $\mathrm{Ni}$ foam electrode and its behaviors in electrochemical reduction of tetrabromobisphenol A, Mater. Lett., 166 (2016) 300-303.

[33] J. Simonet, V. Jouikov, Gold and gold-graphene used as cathodic interfaces for scission of carbon-halogen bonds. Application to the building of anthraquinone-Au electrodes, Electrochem. Commun., 40 (2014) 58-62.

[34] B. Huang, A.A. Isse, C. Durante, C. Wei, A. Gennaro, Electrocatalytic properties of transition metals toward reductive dechlorination of polychloroethanes, Electrochim. Acta, 70 (2012) 50-61.

[35] S.S. Shendage, U.B. Patil, J.M. Nagarkar, Electrochemical synthesis and characterization of palladium nanoparticles on nafion-graphene support and its application for Suzuki coupling reaction, Tetrahedron Lett., 54 (2013) 3457-3461.

[36] U.S. Mohanty, Electrodeposition: a versatile and inexpensive tool for the synthesis of nanoparticles, nanorods, nanowires, and nanoclusters of metals, J. Appl. Electrochem., 41 (2011) 257-270.

[37] V.V. Yanilkin, R.R. Fazleeva, G.R. Nasretdinova, Y.N. Osin, A.T. Gubaidullin, A.Y. Ziganshina, Two-step one-pot electrosynthesis and catalytic activity of $\mathrm{xCoO}-\mathrm{yCo}(\mathrm{OH}) 2-$ supported silver nanoparticles, J. Solid State Electrochem., 24 (2020) 829-842.

[38] Y. Budnikova, O. Bochkova, M. Khrizanforov, I. Nizameev, K. Kholin, T. Gryaznova, A. Laskin, Y. Dudkina, S. Strekalova, S. Fedorenko, A. Kononov, A. Mustafina, Selective C(sp2)-H Amination Catalyzed by High-Valent Cobalt(III)/(IV)-bpy Complex Immobilized on Silica Nanoparticles, ChemCatChem, 11 (2019) 5615-5624.

[39] T.V. Gryaznova, M.N. Khrizanforov, K.V. Kholin, M.A. Vorotyntsev, K.V. Gor'kov, N.V. Talagaeva, M.V. Dmitrieva, E.V. Zolotukhina, Y.H. Budnikova, Palladium Nanoparticles-Polypyrrole Composite as Effective Catalyst for Fluoroalkylation of Alkenes, Catal. Lett., 148 (2018) 3119-3125. 
[40] Y.B. Dudkina, T.V. Gryaznova, Y.N. Osin, V.V. Salnikov, N.A. Davydov, S.V. Fedorenko, A.R. Mustafina, D.A. Vicic, O.G. Sinyashin, Y.H. Budnikova, Nanoheterogeneous catalysis in electrochemically induced olefin perfluoroalkylation, Dalton Transactions, 44 (2015) 8833-8838.

[41] V.V. Yanilkin, N.V. Nastapova, G.R. Nasretdinova, Y.N. Osin, V.G. Evtjugin, A.Y. Ziganshina, A.T. Gubaidullin, Structure and catalytic activity of ultrasmall $\mathrm{Rh}, \mathrm{Pd}$ and $(\mathrm{Rh}+$ Pd) nanoparticles obtained by mediated electrosynthesis, New J. Chem., 43 (2019) 3931-3945.

[42] A.A. Isse, S. Gottardello, C. Maccato, A. Gennaro, Silver nanoparticles deposited on glassy carbon. Electrocatalytic activity for reduction of benzyl chloride, Electrochem. Commun., 8 (2006) 1707-1712.

[43] C. Durante, V. Perazzolo, L. Perini, M. Favaro, G. Granozzi, A. Gennaro, Electrochemical activation of carbon-halogen bonds: Electrocatalysis at silver/copper nanoparticles, Applied Catalysis B: Environmental, 158 (2014) 286-295.

[44] J.M. Unrine, B.P. Colman, A.J. Bone, A.P. Gondikas, C.W Matson, Biotic and Abiotic Interactions in Aquatic Microcosms Determine Fate and Toxicity of Ag Nanoparticles. Part 1. Aggregation and Dissolution, Environ. Sci. Technol., 46 (2012) 6915-6924.

[45] A. Bour, F. Mouchet, J. Silvestre, L. Gauthier, E. Pinelli, Environmentally relevant approaches to assess nanoparticles ecotoxicity: A review, J. Hazard. Mater., 283 (2015) 764777.

[46] Y. Yue, X. Li, L. Sigg, M.J. Suter, S. Pillai, R. Behra, K. Schirmer, Interaction of silver nanoparticles with algae and fish cells: a side by side comparison, Journal of nanobiotechnology, 15 (2017) 16.

[47] L. Perini, C. Durante, M. Favaro, S. Agnoli, G. Granozzi, A. Gennaro, Electrocatalysis at palladium nanoparticles: Effect of the support nitrogen doping on the catalytic activation of carbonhalogen bond, Appl. Catal. B-Environ., 144 (2014) 300-307.

[48] X. Zhao, A. Li, R. Mao, H. Liu, J. Qu, Electrochemical removal of haloacetic acids in a three-dimensional electrochemical reactor with Pd-GAC particles as fixed filler and Pdmodified carbon paper as cathode, Water Res., 51 (2014) 134-143.

[49] N. Singh, B.R. Goldsmith, Role of Electrocatalysis in the Remediation of Water Pollutants, ACS Catal., 10 (2020) 3365-3371.

[50] A. Georgi, F.-D. Kopinke, Interaction of adsorption and catalytic reactions in water decontamination processes. Part I. Oxidation of organic contaminants with hydrogen peroxide catalyzed by activated carbon, Appl. Catal. B-Environ., 58 (2005) 9-18.

[51] A. Gennaro, A.A. Isse, C.L. Bianchi, P.R. Mussini, M. Rossi, Is glassy carbon a really inert electrode material for the reduction of carbon-halogen bonds?, Electrochem. Commun., 11 (2009) 1932-1935.

[52] T. Durkic, A. Peric, M. Lausevic, A. Dekanski, O. Neskovic, M. Veljkovic, Z. Lausevic, Boron and phosphorus doped glassy carbon: I. Surface properties, Carbon, 35 (1997) 15671572.

[53] A. Dekanski, J. Stevanovic, R. Stevanovic, B.Z. Nikolic, V.M. Jovanovic, Glassy carbon electrodes. I. Characterization and electrochemical activation, Carbon, 39 (2001) 1195-1205.

[54] A. Minguzzi, O. Lugaresi, G. Aricci, S. Rondinini, A. Vertova, Silver nanoparticles for hydrodehalogenation reduction: Evidence of a synergistic effect between catalyst and support, Electrochem. Commun., 22 (2012) 25-28. 
[55] X. Mao, A. Ciblak, K. Baek, M. Amiri, R. Loch-Caruso, A.N. Alshawabkeh, Optimization of electrochemical dechlorination of trichloroethylene in reducing electrolytes, Water Res., 46 (2012) 1847-1857.

[56] B. Yang, G. Yu, X. Liu, Electrochemical hydrodechlorination of 4-chlorobiphenyl in aqueous solution with the optimization of palladium-loaded cathode materials, Electrochim. Acta, 52 (2006) 1075-1081.

[57] W. Xie, S. Yuan, X. Mao, W. Hu, P. Liao, M. Tong, A.N. Alshawabkeh, Electrocatalytic activity of Pd-loaded $\mathrm{Ti} / \mathrm{TiO}_{2}$ nanotubes cathode for TCE reduction in groundwater, Water Res., 47 (2013) 3573-3582.

[58] Y. Mohd, D. Pletcher, The fabrication of lead dioxide layers on a titanium substrate, Electrochim. Acta, 52 (2006) 786-793.

[59] M. Musiani, S. Cattarin, S. Cimino, N. Comisso, L. Mattarozzi, L. Vázquez-Gómez, E. Verlato, Preparation of 3D electrocatalysts and catalysts for gas-phase reactions, through electrodeposition or galvanic displacement, J. Appl. Electrochem., 45 (2015) 715-725.

[60] J. Li, H. Liu, X. Cheng, Q. Chen, Y. Xin, Z. Ma, W. Xu, J. Ma, N. Ren, Preparation and characterization of palladium/polypyrrole/foam nickel electrode for electrocatalytic hydrodechlorination, Chem. Eng. J., 225 (2013) 489-498,

[61] J. Li, C. Luan, Y. Cui, H. Zhang, L. Wang, H. Wang, Z. Zhang, B. Zhao, H. Zhang, X. Zhang, X. Cheng, Preparation and characterization of palladium/polyaniline/foamed nickel composite electrode for electrocatalytic dechlorination, Sep. Purif. Technol., 211 (2019) 198206.

[62] H. Cheng, K. Scott, P.A. Christensen, Engineering aspects of electrochemical hydrodehalogenation of 2,4-dichlorophenol in a solid polymer electrolyte reactor, Appl. Catal., A, 261 (2004) 1-6.

[63] L. Vázquez-Gómez, S. Cattarin, N. Comisso, P. Guerriero, M. Musiani, E. Verlato, Spontaneous deposition of $\mathrm{Pd}$ onto $\mathrm{Fe}-\mathrm{Cr}-\mathrm{Al}$ alloys, Electrochim. Acta, 68 (2012) 114-122.

[64] D. Floner, F. Geneste, Homogeneous coating of graphite felt by nickel electrodeposition to achieve light nickel felts with high surface area, Electrochem. Commun., 9 (2007) 22712275.

[65] D. Guo, X. Yu, W. Shi, Y. Luo, Q. Li, T. Wang, Facile synthesis of well-ordered manganese oxide nanosheet arrays on carbon cloth for high-performance supercapacitors, Journal of Materials Chemistry A, 2 (2014) 8833-8838.

[66] M. Chun'an, M. Hao, X. Ying'hua, C. You'qun, Z. Feng'ming, The roughened silverpalladium cathode for electrocatalytic reductive dechlorination of 2,4-Dichlorophenoxyacetic acid, Electrochem. Commun., 11 (2009) 2133-2136.

[67] A.A. Perić-Grujić, O.M. Nešković, M.V. Veljković, Z.V. Laušević, M.D. Laušević, Surface characterization of silver and palladium modified glassy carbon, Bull. Mater. Sci., 30 (2007) 587-593.

[68] M.V. Bagal, P.R. Gogate, Sonochemical degradation of alachlor in the presence of process intensifying additives, Sep. Purif. Technol., 90 (2012) 92-100.

[69] M. Terrones, P.M. Ajayan, F. Banhart, X. Blase, D.L. Carroll, J.C. Charlier, R. Czerw, B. Foley, N. Grobert, R. Kamalakaran, P. Kohler-Redlich, M. Ruhle, T. Seeger, H. Terrones, Ndoping and coalescence of carbon nanotubes: synthesis and electronic properties, Applied Physics A: Materials Science and Processing, 74 (2002) 355-361. 
[70] V. Jouikov, J. Simonet, Reduction of aryl halides at transition metal cathodes. Conditions for aryl-aryl bond formation: The Ullmann's reaction revisited, Electrochem. Commun., 12 (2010) 781-783.

[71] J. Simonet, Glassy carbon electrodes doped by surface graphite nano-flakes: Multi-step redox transitions functionalization, Electrochem. Commun., 30 (2013) 17-20.

[72] C.e.N.e.R. Rao, A.e.K. Sood, K.e.S. Subrahmanyam, A. Govindaraj, Graphene: the new two - dimensional nanomaterial, Angew. Chem. Int. Ed., 48 (2009) 7752-7777.

[73] T. Durkic, A. Peric, M. Lausevic, O. Neskovic, M. Veljkovic, Z. Lausevic, Study of the surface of glassy carbon oxidized at low temperatures, Tehnika (Belgrade), 52 (1997) NM5NM8.

[74] J. Huang, Y. Wu, D. Wang, Y. Ma, Z. Yue, Y. Lu, M. Zhang, Z. Zhang, P. Yang, Silicon phthalocyanine covalently functionalized $\mathrm{N}$-doped ultrasmall reduced graphene oxide decorated with Pt nanoparticles for hydrogen evolution from water, ACS applied materials and interfaces, 7 (2015) 3732-3741.

[75] C. Sun, S.A. Baig, Z. Lou, J. Zhu, Z. Wang, X. Li, J. Wu, Y. Zhang, X. Xu, Electrocatalytic dechlorination of 2, 4-dichlorophenoxyacetic acid using nanosized titanium nitride doped palladium/nickel foam electrodes in aqueous solutions, Applied Catalysis B: Environmental, 158 (2014) 38-47.

[76] H.O. Pierson, Handbook of carbon, graphite, diamonds and fullerenes: processing, properties and applications, Noyes Publications, New Jersey, 1994.

[77] Y.Z. Wan, Y.L. Wang, G.J. Li, H.L. Luo, G.X. Cheng, Carbon fibre felt electrodeposited by copper and its composites, J. Mater. Sci. Lett., 16 (1997) 1561-1563.

[78] R. Abdallah, F. Geneste, T. Labasque, H. Djelal, F. Fourcade, A. Amrane, S. Taha, D. Floner, Selective and quantitative nitrate electroreduction to ammonium using a porous copper electrode in an electrochemical flow cell, J. Electroanal. Chem., 727 (2014) 148-153.

[79] Y. Lou, D. Fu, B. Fabre, F. Fourcade, A. Amrane, M. Pasturel, R. Bourzami, O. Merdrignac-Conanec, T. Labasque, F. Geneste, Bismuth coated graphite felt modified by silver particles for selective electroreduction of $\mathrm{CO} 2$ into formate in a flow cell, Electrochim. Acta, (2021) 137821.

[80] A.M. Mishura, A.S. Lytvynenko, K.S. Gavrilenko, A.E. Baranchikov, N.V. Grabovaya, M.A. Kiskin, S.V. Kolotilov, Formation of hierarchically-ordered nanoporous silver foam and its electrocatalytic properties in reductive dehalogenation of organic compounds, New J. Chem., 42 (2018) 17499-17512.

[81] A.A. Ensafi, M. Jafari-Asl, B. Rezaei, Graphene/nano-porous silicon and graphene/bimetallic silicon nanostructures (Pt-M, M: $\mathrm{Pd}, \mathrm{Ru}, \mathrm{Rh})$, efficient electrocatalysts for the hydrogen evolution reaction, Phys. Chem. Chem. Phys., 17 (2015) 23770-23782.

[82] W. Feng, L. Yang, N. Cao, C. Du, H. Dai, W. Luo, G. Cheng, In situ facile synthesis of bimetallic CoNi catalyst supported on graphene for hydrolytic dehydrogenation of amine borane, Int. J. Hydrogen Energy, 39 (2014) 3371-3380.

[83] C.L. Lee, C.M. Tseng, C.C. Wu, Catalytic activity of Ag - Pd nanoparticles prepared by $\mathrm{N}_{2} \mathrm{H}_{4}$ reduction in electroless nickel deposition, J. Chin. Inst. Eng., 33 (2010) 105-109.

[84] H. Wang, J. Wang, Comparative study on electrochemical degradation of 2,4dichlorophenol by different $\mathrm{Pd} / \mathrm{C}$ gas-diffusion cathodes, Applied Catalysis B: Environmental, 89 (2009) 111-117. 
[85] C. Sun, Z. Lou, Y. Liu, R. Fu, X. Zhou, Z. Zhang, S.A. Baig, X. Xu, Influence of environmental factors on the electrocatalytic dechlorination of 2, 4-dichlorophenoxyacetic acid on nTiN doped Pd/Ni foam electrode, Chem. Eng. J., 281 (2015) 183-191.

[86] J. Simonet, The one electron reduction of primary alkyl iodides at palladiated surfaces. A convenient and general source of alkyl radicals, J. Electroanal. Chem., 583 (2005) 34-45.

[87] E. Verlato, W. He, A. Amrane, S. Barison, D. Floner, F. Fourcade, F. Geneste, M. Musiani, R. Seraglia, Preparation of Silver - Modified Nickel Foams by Galvanic Displacement and Their Use as Cathodes for the Reductive Dechlorination of Herbicides, ChemElectroChem, 3 (2016) 2084-2092.

[88] P.M. Uberman, L.A. Pérez, G.I. Lacconi, S.E. Martín, PVP-stabilized palladium nanoparticles electrochemically obtained as effective catalysts in aqueous medium SuzukiMiyaura reaction, J. Mol. Catal. A: Chem., 363 (2012) 245-253.

[89] Z.-R. Sun, H. Ge, X. Hu, Y.-Z. Peng, Preparation of foam-nickel composite electrode and its application to 2,4-dichlorophenol dechlorination in aqueous solution, Sep. Purif. Technol., 72 (2010) 133-139.

[90] B. Liu, C. Ding, B. Xiao, L. Cui, M. Wang, Electrocatalytic dechlorination of chloroacetic acids on silver nanodendrites electrode, Mater. Sci. Eng., C, 37 (2014) 108-112.

[91] J.E. Yanez H, Z. Wang, S. Lege, M. Obst, S. Roehler, C.J. Burkhardt, C. Zwiener, Application and characterization of electroactive membranes based on carbon nanotubes and zerovalent iron nanoparticles, Water Res., 108 (2017) 78-85.

[92] Z. Sun, X. Wei, Y. Han, S. Tong, X. Hu, Complete dechlorination of 2, 4-dichlorophenol in aqueous solution on palladium/polymeric pyrrole-cetyl trimethyl ammonium bromide/foam-nickel composite electrode, J. Hazard. Mater., 244 (2013) 287-294.

[93] G. Zhang, Y. Kuang, J. Liu, Y. Cui, J. Chen, H. Zhou, Fabrication of Ag/Au bimetallic nanoparticles by UPD-redox replacement: Application in the electrochemical reduction of benzyl chloride, Electrochem. Commun., 12 (2010) 1233-1236.

[94] A. Li, X. Zhao, Y. Hou, H. Liu, L. Wu, J. Qu, The electrocatalytic dechlorination of chloroacetic acids at electrodeposited $\mathrm{Pd} / \mathrm{Fe}$-modified carbon paper electrode, Applied Catalysis B: Environmental, 111 (2012) 628-635.

[95] N. Vatistas, S. Cristofaro, Lead dioxide coating obtained by pulsed current technique, Electrochem. Commun., 2 (2000) 334-337.

[96] Z. He, Q. Jian, J. Tang, T. Xu, J. Xu, Z. Yu, J. Chen, S. Song, Improvement of electrochemical reductive dechlorination of 2, 4-dichlorophenoxyacetic acid using palladium catalysts prepared by a pulsed electrodeposition method, Electrochim. Acta, 222 (2016) 488498.

[97] Z. Sun, G. Song, R. Du, X. Hu, Modification of a Pd-loaded electrode with a carbon nanotubes-polypyrrole interlayer and its dechlorination performance for 2,3-dichlorophenol, RSC Adv., 7 (2017) 22054-22062.

[98] L.K. Yamada, A.G. da Silva, T.S. Rodrigues, S.J. Haigh, P.H. Camargo, Bimetallic Au@ Pd - Au Tadpole - Shaped Asymmetric Nanostructures by a Combination of Precursor Reduction and Ostwald Ripening, ChemNanoMat, 2 (2016) 509-514.

[99] Y. Liu, R. Mao, Y. Tong, H. Lan, G. Zhang, H. Liu, J. Qu, Reductive dechlorination of trichloroacetic acid (TCAA) by electrochemical process over Pd-In/Al2O3 catalyst, Electrochim. Acta, 232 (2017) 13-21. 
[100] Y. Wu, L. Gan, S. Zhang, H. Song, C. Lu, W. Li, Z. Wang, B. Jiang, A. Li, Carbonnanotube-doped $\mathrm{Pd}-\mathrm{Ni}$ bimetallic three-dimensional electrode for electrocatalytic hydrodechlorination of 4-chlorophenol: Enhanced activity and stability, J. Hazard. Mater., 356 (2018) 17-25.

[101] Z. Sun, X. Wei, H. Shen, X. Hu, Preparation of palladium-nickel loaded titanium electrode with surfactant assistance and its application in pentachlorophenol reductive dechlorination, Sep. Purif. Technol., 124 (2014) 224-230.

[102] Y. Liu, Y. Zhang, H. Hua, Y. Li, Fabrication of single Pt@ Au nanowire electrodes for monitoring hydrogen peroxide released from living cells, RSC Advances, 7 (2017) 4455244558.

[103] Y. Yu, Y. Hu, X. Liu, W. Deng, X. Wang, The study of Pt@ Au electrocatalyst based on $\mathrm{Cu}$ underpotential deposition and Pt redox replacement, Electrochim. Acta, 54 (2009) 3092-3097.

[104] Y. Lu, S. Jiang, Y. Huang, Ultrasonic-assisted electroles deposition of Ag on PET fabric with low silver content for EMI shielding, Surf. Coat. Technol., 204 (2010) 2829-2833.

[105] T.J. Mason, J.P. Lorimer, Applied sonochemistry: the uses of power ultrasound in chemistry and processing, Wiley - VCH Verlag, Weinheim, 2002.

[106] B. Macijauskienè, E. Griškonis, Ultrasound assisted modification of graphite felt with electroless silver-Part 1: composition, morphology, structure and electrical conductivity, Chemija, 26 (2015) 1-8.

[107] N.V. Nastapova, G.R. Nasretdinova, Y.N. Osin, A.T. Gubaidullin, V.V. Yanilkin, TwoStep Mediated Electrosynthesis and Catalytic Activity of Au/Cu2O@poly(N-vinylpyrrolidone) Nanocomposite, ECS Journal of Solid State Science and Technology, 9 (2020) 061007.

[108] V.V. Yanilkin, R.R. Fazleeva, G.R. Nasretdinova, Y.N. Osin, N.A. Zhukova, V.A. Mamedov, Benzimidazo[1',2':1,2]Quinolino[4,3-b][1,2,5]Oxodiazolo[3,4-f]QuinoxalineNew Mediator for Electrosynthesizing Metal Nanoparticles, Russ. J. Electrochem., 56 (2020) 646-659.

[109] R.R. Fazleeva, G.R. Nasretdinova, Y.N. Osin, A.I. Samigullina, A.T. Gubaidullin, V.V. Yanilkin, $\mathrm{CoO}-\mathrm{xCo}(\mathrm{OH}) 2$ supported silver nanoparticles: electrosynthesis in acetonitrile and catalytic activity, Mendeleev Commun., 30 (2020) 456-458.

[110] H. Zhou, J. Han, S.A. Baig, X. Xu, Dechlorination of 2,4-dichlorophenoxyacetic acid by sodium carboxymethyl cellulose-stabilized Pd/Fe nanoparticles, J. Hazard. Mater., 198 (2011) 7-12.

[111] G.R. Nasretdinova, R.R. Fazleeva, Y.N. Osin, V.G. Evtjugin, A.T. Gubaidullin, A.Y. Ziganshina, V.V. Yanilkin, Methylviologen mediated electrochemical synthesis of catalytically active ultrasmall bimetallic PdAg nanoparticles stabilized by CTAC, Electrochim. Acta, 285 (2018) 149-163.

[112] Z. Zhang, B. Zhao, L. Hu, PVP protective mechanism of ultrafine silver powder synthesized by chemical reduction processes, J. Solid State Chem., 121 (1996) 105-110.

[113] H. Wang, X. Qiao, J. Chen, X. Wang, S. Ding, Mechanisms of PVP in the preparation of silver nanoparticles, Mater. Chem. Phys., 94 (2005) 449-453.

[114] J. Li, H. Liu, X. Cheng, Y. Xin, W. Xu, Z. Ma, J. Ma, N. Ren, Q. Li, Stability of Palladium-Polypyrrole-Foam Nickel Electrode and Its Electrocatalytic Hydrodechlorination for Dichlorophenol Isomers, Ind. Eng. Chem. Res., 51 (2012) 15557-15563. 
[115] O. Bochkova, M. Khrizanforov, A. Gubaidullin, T. Gerasimova, I. Nizameev, K. Kholin, A. Laskin, Y. Budnikova, O. Sinyashin, A. Mustafina, Synthetic Tuning of CoII-Doped Silica Nanoarchitecture Towards Electrochemical Sensing Ability, Nanomaterials, 10 (2020).

[116] V.V. Yanilkin, N.V. Nastapova, G.R. Nasretdinova, R.R. Fazleeva, Y.N. Osin, Molecular oxygen as a mediator in the electrosynthesis of gold nanoparticles in DMF, Electrochem. Commun., 69 (2016) 36-40.

[117] G.K. Williamson, W.H. Hall, X-ray line broadening from filed aluminum and tungsten, Acta Metall., 1 (1953) 22-31.

[118] W. Keely, X-Ray Diffraction Technique for Rapid Surface Area Determination, Anal. Chem., 38 (1966) 147-148.

[119] F.W. Campbell, R.G. Compton, Contrasting underpotential depositions of lead and cadmium on silver macroelectrodes and silver nanoparticle electrode arrays, Int. J. Electrochem. Sci, 5 (2010) 407-413.

[120] P. Singh, D.A. Buttry, Comparison of oxygen reduction reaction at silver nanoparticles and polycrystalline silver electrodes in alkaline solution, Journal of Physical Chemistry C, 116 (2012) 10656-10663.

[121] S. Cimino, L. Lisi, G. Mancino, M. Musiani, L. Vázquez-Gómez, E. Verlato, Catalytic partial oxidation of $\mathrm{CH}_{4}-\mathrm{H}_{2}$ mixtures over $\mathrm{Ni}$ foams modified with $\mathrm{Rh}$ and $\mathrm{Pt}$, Int. J. Hydrogen Energy, 37 (2012) 17040-17051.

[122] A.N. Correia, L.H. Mascaro, S.A.S. machado, L.A. Avaca, Active surface area determination of Pd-Si alloys by H-adsorption, Electrochim. Acta, 42 (1996) 493-495.

[123] A. Pozio, M. De Francesco, A. Cemmi, F. Cardellini, L. Giorgi, Comparison of high surface Pt/C catalysts by cyclic voltammetry, J. Power Sources, 105 (2002) 13-19.

[124] J. Perez, E. Gonzalez, E. Ticianelli, Oxygen electrocatalysis on thin porous coating rotating platinum electrodes, Electrochim. Acta, 44 (1998) 1329-1339.

[125] A.J. Bard, L.R. Faulkner, Electrochemical Methods: Fundamentals and Applications, John Wiley \& Sons, New York, 1982.

[126] F.W. Campbell, S.R. Belding, R. Baron, L. Xiao, R.G. Compton, Hydrogen peroxide electroreduction at a silver-nanoparticle array: investigating nanoparticle size and coverage effects, Journal of Physical Chemistry C, 113 (2009) 9053-9062.

[127] V. Bansal, V. Li, A.P. O'Mullane, S.K. Bhargava, Shape dependent electrocatalytic behaviour of silver nanoparticles, CrystEngComm, 12 (2010) 4280-4286.

[128] A.I. Tsyganok, K. Otsuka, Electrocatalytic reductive dehalogenation of 2, 4-D in aqueous solution on carbon materials containing supported palladium, Electrochim. Acta, 43 (1998) 2589-2596.

[129] Y. Xu, Y. Zhu, F. Zhao, C.-a. Ma, Electrocatalytic reductive dehalogenation of polyhalogenated phenols in aqueous solution on Ag electrodes, Applied Catalysis A: General, 324 (2007) 83-86.

[130] J. Li, H. Liu, X. Cheng, Y. Xin, W. Xu, Z. Ma, J. Ma, N. Ren, Q. Li, Stability of palladium-polypyrrole-foam nickel electrode and its electrocatalytic hydrodechlorination for dichlorophenol isomers, Ind. Eng. Chem. Res., 51 (2012) 15557-15563. 
[131] S. Rondinini, P.R. Mussini, M. Specchia, A. Vertova, The electrocatalytic performance of silver in the reductive dehalogenation of bromophenols, J. Electrochem. Soc., 148 (2001) D102-D107.

[132] S.B. Rondinini, P.R. Mussini, F. Crippa, G. Sello, Electrocatalytic potentialities of silver as a cathode for organic halide reductions, Electrochem. Commun., 2 (2000) 491-496.

[133] C. Bellomunno, D. Bonanomi, L. Falciola, M. Longhi, P.R. Mussini, L.M. Doubova, G. Di Silvestro, Building up an electrocatalytic activity scale of cathode materials for organic halide reductions, Electrochim. Acta, 50 (2005) 2331-2341.

[134] A.A. Isse, B. Huang, C. Durante, A. Gennaro, Electrocatalytic dechlorination of volatile organic compounds at a copper cathode. Part I: Polychloromethanes, Applied Catalysis B: Environmental, 126 (2012) 347-354.

[135] C. Durante, B. Huang, A.A. Isse, A. Gennaro, Electrocatalytic dechlorination of volatile organic compounds at copper cathode. Part II: Polychloroethanes, Applied Catalysis B: Environmental, 126 (2012) 355-362.

[136] S. Rondinini, P.R. Mussini, P. Muttini, G. Sello, Silver as a powerful electrocatalyst for organic halide reduction: the critical role of molecular structure, Electrochim. Acta, 46 (2001) 3245-3258.

[137] H. Yin, X. Cao, C. Lei, W. Chen, B. Huang, Insights into Electroreductive Dehalogenation Mechanisms of Chlorinated Environmental Pollutants, ChemElectroChem, 7 (2020) 1825-1837.

[138] C. Lei, F. Liang, J. Li, W. Chen, B. Huang, Electrochemical reductive dechlorination of chlorinated volatile organic compounds (Cl-VOCs): Effects of molecular structure on the dehalogenation reactivity and mechanisms, Chem. Eng. J., 358 (2019) 1054-1064.

[139] M.L. Foresti, M. Innocenti, F. Forni, R. Guidelli, Electrosorption Valency and Partial Charge Transfer in Halide and Sulfide Adsorption on $\operatorname{Ag}(111)$, Langmuir, 14 (1998) 70087016.

[140] S. Ardizzone, G. Cappelletti, L.M. Doubova, P.R. Mussini, S.M. Passeri, S. Rondinini, The role of surface morphology on the electrocatalytic reduction of organic halides on monoand polycrystalline silver, Electrochim. Acta, 48 (2003) 3789-3796.

[141] A.A. Isse, S. Gottardello, C. Durante, A. Gennaro, Dissociative electron transfer to organic chlorides: Electrocatalysis at metal cathodes, Phys. Chem. Chem. Phys., 10 (2008) 2409-2416.

[142] A.A. Isse, G. Berzi, L. Falciola, M. Rossi, P.R. Mussini, A. Gennaro, Electrocatalysis and electron transfer mechanisms in the reduction of organic halides at Ag, J. Appl. Electrochem., 39 (2009) 2217-2225.

[143] A.A. Isse, P.R. Mussini, A. Gennaro, New insights into electrocatalysis and dissociative electron transfer mechanisms: The case of aromatic bromides, Journal of Physical Chemistry C, 113 (2009) 14983-14992.

[144] L. Nadjo, J. Savéant, Linear sweep voltammetry: Kinetic control by charge transfer and/or secondary chemical reactions: I. Formal kinetics, Journal of Electroanalytical Chemistry and Interfacial Electrochemistry, 48 (1973) 113-145.

[145] S. Ardizzone, G. Cappelletti, P.R. Mussini, S. Rondinini, L.M. Doubova, Adsorption competition effects in the electrocatalytic reduction of organic halides on silver, J. Electroanal. Chem., 532 (2002) 285-293. 
[146] R.F.M. de Souza, M. Laurent, E. Leonel, C. Cachet-Vivier, C.A. de Souza, M.C.C. Areias, L.W. Bieber, M. Navarro, Electrochemical reduction of benzyl chloride on silver, graphite, and silver/graphite powder macroelectrodes, Electrochim. Acta, 167 (2015) 105-111.

[147] C. Durante, A.A. Isse, G. Sandona, A. Gennaro, Electrochemical hydrodehalogenation of polychloromethanes at silver and carbon electrodes, Appl. Catal., B, 88 (2009) 479-489.

[148] O. Scialdone, C. Guarisco, A. Galia, R. Herbois, Electroreduction of aliphatic chlorides at silver cathodes in water, J. Electroanal. Chem., 641 (2010) 14-22.

[149] G.-J. Sui, Q.-L. Sun, D. Wu, W.-J. Meng, H. Wang, J.-X. Lu, Electrocatalytic reduction of PhCH2Cl on Ag-ZSM-5 zeolite modified electrode, RSC Advances, 6 (2016) 63493-63496.

[150] M.D. Esclapez, M.I. Díez-García, V. Sáez, I. Tudela, J.M. Pérez, J. González-García, P. Bonete, Spectroelectrochemical study of trichloroacetic acid reduction at copper electrodes in an aqueous sodium sulfate medium, Electrochim. Acta, 56 (2011) 8138-8146.

[151] X. Wei, X. Wan, Z. Sun, J. Miao, R. Zhang, Q.J. Niu, Understanding Electrocatalytic Hydrodechlorination of Chlorophenols on Palladium-Modified Cathode in Aqueous Solution, ACS Omega, 3 (2018) 5876-5886.

[152] G. Jiang, X. Li, Y. Shen, X. Shi, X. Lv, X. Zhang, F. Dong, G. Qi, R. Liu, Mechanistic insight into the electrocatalytic hydrodechlorination reaction on palladium by a facet effect study, J. Catal., 391 (2020) 414-423.

[153] T. Li, J. Farrell, Reductive dechlorination of trichloroethene and carbon tetrachloride using iron and palladized-iron cathodes, Environ. Sci. Technol., 34 (2000) 173-179.

[154] G. Jiang, K. Wang, J. Li, W. Fu, Z. Zhang, G. Johnson, X. Lv, Y. Zhang, S. Zhang, F. Dong, Electrocatalytic hydrodechlorination of 2,4-dichlorophenol over palladium nanoparticles and its pH-mediated tug-of-war with hydrogen evolution, Chem. Eng. J., 348 (2018) 26-34.

[155] S.A. Pandit, S.A. Bhat, M.A. Rather, P.P. Ingole, M.A. Bhat, Mechanistic insight into the electrocatalytic performance of reduced graphene oxide supported palladium, silver and palladium-silver nanodeposits toward electro-dehalogenation of halocarbons in room temperature ionic liquids, PCCP, 22 (2020) 16985-16997.

[156] H. Kobayashi, M. Yamauchi, H. Kitagawa, Y. Kubota, K. Kato, M. Takata, On the Nature of Strong Hydrogen Atom Trapping Inside Pd Nanoparticles, J. Am. Chem. Soc., 130 (2008) 1828-1829.

[157] M. Yamauchi, R. Ikeda, H. Kitagawa, M. Takata, Nanosize Effects on Hydrogen Storage in Palladium, J. Phys. Chem. C, 112 (2008) 3294-3299.

[158] H. Lee, Utilization of shape-controlled nanoparticles as catalysts with enhanced activity and selectivity, RSC Adv., 4 (2014) 41017-41027.

[159] M.-H. Shao, T.-Y. Yu, J.H. Odell, M.-S. Jin, Y.-N. Xia, Structural dependence of oxygen reduction reaction on palladium nanocrystals, Chem. Commun., 47 (2011) 6566-6568.

[160] C. Jiang, H. Yu, Y. Lu, S. Zhu, Z. Geng, M. Huo, X. Wang, Preparation of spike-like palladium nanoparticle electrode and its dechlorination properties, Thin Solid Films, 664 (2018) 27-32.

[161] J. Zhou, Z. Lou, K. Yang, J. Xu, Y. Li, Y. Liu, S.A. Baig, X. Xu, Electrocatalytic dechlorination of 2,4-dichlorobenzoic acid using different carbon-supported palladium 
moveable catalysts: Adsorption and dechlorination activity, Applied Catalysis B: Environmental, 244 (2019) 215-224.

[162] X. Ma, Z. Sun, X. Hu, Electrocatalytic dechlorination of chlorophenols on palladium/graphene-Nafion/titanium mesh electrode, Journal of Water Process Engineering, 26 (2018) 72-82.

[163] S.A. Bhat, N. Rashid, M.A. Rather, S.A. Pandit, G.M. Rather, P.P. Ingole, M.A. Bhat, PdAg Bimetallic Nanoalloy-Decorated Graphene: A Nanohybrid with Unprecedented Electrocatalytic, Catalytic, and Sensing Activities, ACS Applied Materials \& Interfaces, 10 (2018) 16376-16389.

[164] R. Mao, C. Huang, X. Zhao, M. Ma, J. Qu, Dechlorination of triclosan by enhanced atomic hydrogen-mediated electrochemical reduction: Kinetics, mechanism, and toxicity assessment, Applied Catalysis B: Environmental, 241 (2019) 120-129.

[165] Z. Lou, Y. Li, J. Zhou, K. Yang, Y. Liu, S.A. Baig, X. Xu, TiC doped palladium/nickel foam cathode for electrocatalytic hydrodechlorination of 2,4-DCBA: Enhanced electrical conductivity and reactive activity, J. Hazard. Mater., 362 (2019) 148-159.

[166] Z. Lou, Z. Wang, J. Zhou, C. Zhou, J. Xu, X. Xu, Pd/TiC/Ti electrode with enhanced atomic $\mathrm{H}^{*}$ generation, atomic $\mathrm{H}^{*}$ adsorption and 2,4-DCBA adsorption for facilitating electrocatalytic hydrodechlorination, Environmental Science: Nano, 7 (2020) 1566-1581.

[167] F. Urbano, J. Marinas, Hydrogenolysis of organohalogen compounds over palladium supported catalysts, J. Mol. Catal. A: Chem., 173 (2001) 329-345.

[168] N. Korte, O. West, L. Liang, B. Gu, J. Zutman, Q. Fernando, The effect of solvent concentration on the use of palladized-iron for the step-wise dechlorination of polychlorinated biphenyls in soil extracts, Waste Manag., 22 (2002) 343-349.

[169] J. Han, R.L. Deming, F.-M. Tao, Theoretical study of molecular structures and properties of the complete series of chlorophenols, J. Phys. Chem. A, 108 (2004) 7736-7743.

[170] S.J. Blanksby, G.B. Ellison, Bond dissociation energies of organic molecules, Acc. Chem. Res., 36 (2003) 255-263.

[171] B. Vanrenterghem, A. Papaderakis, S. Sotiropoulos, D. Tsiplakides, S. Balomenou, S. Bals, T. Breugelmans, The reduction of benzylbromide at Ag-Ni deposits prepared by galvanic replacement, Electrochim. Acta, 196 (2016) 756-768.

[172] H. Baltruschat, S. Ernst, N. Bogolowski, Electrocatalysis at bimetallic surfaces obtained by surface decoration, in: E. Santos, W. Schmickler (Eds.) Catalysis in Electrochemistry: From Fundamentals to Strategies for Fuel Cell Development, John Wiley \& Sons, New Jersey, 2011, pp. 297-337.

[173] B. Vanrenterghem, B. Geboes, S. Bals, J. Ustarroz, A. Hubin, T. Breugelmans, Influence of the support material and the resulting particle distribution on the deposition of $\mathrm{Ag}$ nanoparticles for the electrocatalytic activity of benzyl bromide reduction, Applied Catalysis B: Environmental, 181 (2016) 542-549.

[174] H.-h. Zhou, Y.-1. Li, J.-q. Huang, C.-x. Fang, D. Shan, Y.-f. Kuang, Ag-Ni alloy nanoparticles for electrocatalytic reduction of benzyl chloride, Trans. Nonferrous Met. Soc. China, 25 (2015) 4001-4007.

[175] B. Yang, R. Burch, C. Hardacre, G. Headdock, P. Hu, Origin of the Increase of Activity and Selectivity of Nickel Doped by $\mathrm{Au}, \mathrm{Ag}$, and $\mathrm{Cu}$ for Acetylene Hydrogenation, ACS Catal., 2 (2012) 1027-1032. 
[176] Z. He, L. Zhan, Q. Wang, S. Song, J. Chen, K. Zhu, X. Xu, W. Liu, Increasing the activity and stability of chemi-deposited palladium catalysts on nickel foam substrate by electrochemical deposition of a middle coating of silver, Sep. Purif. Technol., 80 (2011) 526532.

[177] Z. Lou, J. Zhou, M. Sun, J. Xu, K. Yang, D. Lv, Y. Zhao, X. Xu, MnO2 enhances electrocatalytic hydrodechlorination by $\mathrm{Pd} / \mathrm{Ni}$ foam electrodes and reduces Pd needs, Chem. Eng. J., 352 (2018) 549-557.

[178] Z. Lou, J. Xu, J. Zhou, K. Yang, Z. Cao, Y. Li, Y. Liu, L. Lou, X. Xu, Insight into atomic $\mathrm{H}^{*}$ generation, $\mathrm{H} 2$ evolution, and cathode potential of $\mathrm{MnO} 2$ induced $\mathrm{Pd} / \mathrm{Ni}$ foam cathode for electrocatalytic hydrodechlorination, Chem. Eng. J., 374 (2019) 211-220.

[179] G.P. Sakellaropoulos, S.H. Langer, Electrocatalysis; selective electrogenerative reduction of organic halides, J. Catal., 44 (1976) 25-39.

[180] Z. He, K. Lin, J. Sun, L. Wen, C. Gao, J. Chen, S. Song, Y. Qian, W. Liu, Kinetics of electrochemical dechlorination of 2-chlorobiphenyl on a palladium-modified nickel foam cathode in a basic medium: From batch to continuous reactor operation, Electrochim. Acta, 109 (2013) 502-511.

[181] P.R. Mussini, S. Ardizzone, G. Cappelletti, M. Longhi, S. Rondinini, L.M. Doubova, Surface screening effects by specifically adsorbed halide anions in the electrocatalytic reduction of a model organic halide at mono- and polycrystalline silver in acetonitrile, J. Electroanal. Chem., 552 (2003) 213-221.

[182] M. Chen, S. Shu, J. Li, X. Lv, F. Dong, G. Jiang, Activating palladium nanoparticles via a Mott-Schottky heterojunction in electrocatalytic hydrodechlorination reaction, J. Hazard. Mater., 389 (2020) 121876.

[183] C. Schuth, N.-A. Kummer, C. Weidenthaler, H. Schad, Field application of a tailored catalyst for hydrodechlorinating chlorinated hydrocarbon contaminants in groundwater, Applied Catalysis B: Environmental, 52 (2004) 197-203.

[184] B.P. Chaplin, J.R. Shapley, C.J. Werth, Regeneration of Sulfur-Fouled Bimetallic PdBased Catalysts, Environ. Sci. Technol., 41 (2007) 5491-5497.

[185] A.A. Isse, A. De Giusti, A. Gennaro, L. Falciola, P.R. Mussini, Electrochemical reduction of benzyl halides at a silver electrode, Electrochim. Acta, 51 (2006) 4956-4964.

[186] G.V. Lowry, M. Reinhard, Pd-Catalyzed TCE Dechlorination in Water: Effect of $\left[\mathrm{H}_{2}\right](\mathrm{aq})$ and $\mathrm{H}_{2}$-Utilizing Competitive Solutes on the TCE Dechlorination Rate and Product Distribution, Environ. Sci. Technol., 35 (2001) 696-702.

[187] K.N. Heck, M.O. Nutt, P. Alvarez, M.S. Wong, Deactivation resistance of Pd/Au nanoparticle catalysts for water-phase hydrodechlorination, J. Catal., 267 (2009) 97-104.

[188] A.I. Tsyganok, K. Otsuka, Selective dechlorination of chlorinated phenoxy herbicides in aqueous medium by electrocatalytic reduction over palladium-loaded carbon felt, Applied Catalysis B: Environmental, 22 (1999) 15-26.

[189] C. Cui, X. Quan, S. Chen, H. Zhao, Adsorption and electrocatalytic dechlorination of pentachlorophenol on palladium-loaded activated carbon fibers, Sep. Purif. Technol., 47 (2005) 73-79.

[190] B. Yang, G. Yu, D. Shuai, Electrocatalytic hydrodechlorination of 4-chlorobiphenyl in aqueous solution using palladized nickel foam cathode, Chemosphere, 67 (2007) 1361-1367. 
[191] W. He, Y. Lou, E. Verlato, I. Soutrel, D. Floner, F. Fourcade, A. Amrane, M. Musiani, F. Geneste, Reductive dehalogenation of a chloroacetanilide herbicide in a flow electrochemical cell fitted with Ag - modified Ni foams, J. Chem. Technol. Biotechnol., 93 (2018) 1572-1578.

[192] Y.-Y. Lou, W. He, E. Verlato, M. Musiani, D. Floner, F. Fourcade, A. Amrane, C. Li, Z.-Q. Tian, O. Merdrignac-Conanec, Ni-coated graphite felt modified with Ag nanoparticles: A new electrode material for electro-reductive dechlorination, J. Electroanal. Chem., 849 (2019) 113357.

[193] Y.-Y. Lou, P. Hapiot, D. Floner, F. Fourcade, A. Amrane, F. Geneste, Efficient Dechlorination of $\alpha$-Halocarbonyl and $\alpha$-Haloallyl Pollutants by Electroreduction on Bismuth, Environ. Sci. Technol., 54 (2019) 559-567.

[194] B. Liu, X. Hu, Y. Deng, S. Yang, C. Sun, Electrocatalytic dechlorination of chloroacetic acids by silver nanoparticles modified glassy carbon electrode, J. Solid State Electrochem., 16 (2012) 927-930.

[195] S. Rondinini, G. Aricci, Ž. Krpetić, C. Locatelli, A. Minguzzi, F. Porta, A. Vertova, Electroreductions on Silver-Based Electrocatalysts: The Use of Ag Nanoparticles for $\mathrm{CHCl}_{3}$ to $\mathrm{CH}_{4}$ Conversion, Fuel Cells, 9 (2009) 253-263.

[196] E. Escobedo, J. Kim, D. Oh, K. Cho, Y.-S. Chang, Electrocatalytic dehalogenation of aqueous pollutants by dealloyed nanoporous Pd/Ti cathode, Catal. Today, 361 (2021) 63-68.

[197] Y. Wu, L. Gan, S. Zhang, B. Jiang, H. Song, W. Li, Y. Pan, A. Li, Enhanced electrocatalytic dechlorination of para-chloronitrobenzene based on $\mathrm{Ni} / \mathrm{Pd}$ foam electrode, Chem. Eng. J., 316 (2017) 146-153.

[198] J. Li, H. Wang, L. Wang, C. Ma, C. Luan, B. Zhao, Z. Zhang, H. Zhang, X. Cheng, J. Liu, The Preparation of Pd/Foam-Ni Electrode and Its Electrocatalytic Hydrodechlorination for Monochlorophenol Isomers, Catalysts, 8 (2018).

[199] Y. Wang, C. Cui, G. Zhang, Y. Xin, S. Wang, Electrocatalytic hydrodechlorination of pentachlorophenol on Pd-supported magnetic biochar particle electrodes, Sep. Purif. Technol., 258 (2021) 118017.

[200] M. Zaghdoudi, L. Moreaud, P. Even-Hernandez, V. Marchi, F. Fourcade, A. Amrane, H. Maghraoui-Meherzi, F. Geneste, Immobilization of synthetic gold nanoparticles on a threedimensional porous electrode, Electrochem. Commun., 88 (2018) 15-18. 